\title{
Effect of height-to-width ratio on the sound propagation in
}

\section{urban streets}

Pyoung Jik Lee ${ }^{\mathrm{a}, \mathrm{b}}$ and Jian Kang ${ }^{\mathrm{c}}$

a Acoustics Research Unit, School of Architecture, University of Liverpool, Liverpool, L69 7ZN, United Kingdom

${ }^{b}$ EMPA, Swiss Federal Laboratories for Materials Science and Technology, 8600 Dübendorf, Switzerland

${ }^{\text {c }}$ School of Architecture, University of Sheffield, Western Bank, Sheffield S10 2TN, United Kingdom

Running title: Sound propagation in urban streets

Send correspondence to: Pyoung Jik Lee (P.J.Lee@liverpool.ac.uk)

Acoustics Research Unit, School of Architecture, University of Liverpool, Liverpool, L69 7ZN, UK 


\section{Summary}

Street geometry is one of main issues on urban design which influence sound environment as well as urban climate in a street canyon. A parametric study was performed in order to investigate the influence of height-to-width ratio (H/W) on sound fields in urban streets in terms of sound pressure level (SPL), reverberation time (T30), and early decay time (EDT). A computer simulation technique based on a hybrid method combining ray tracing and image source modeling was adopted, and an omnidirectional sound source was used. Four typical idealized urban streets were modeled, with street widths of $6 \mathrm{~m}, 13 \mathrm{~m}, 20 \mathrm{~m}$, and $27 \mathrm{~m}$, respectively. The H/W ratio was then changed in seven steps with varying building heights while the widths of streets were fixed. Comparisons with experimental studies showed that the computer simulation models produce reliable results for SPL and T30. It was found that the variation of SPL was affected by the H/W ratio only for narrow urban streets, and the T30 and EDT increased with an increase in the H/W ratio for both narrow and wide streets. It was also observed that the T30 decreased with increasing scattering coefficients, and the EDT significantly increased as scattering coefficients increased for $\mathrm{H} / \mathrm{W}$ of 3 and 6 . A line source representing road traffic noise was found to produce different tendencies in SPL and EDT, showing that SPL and EDT were relatively constant along the length. 


\section{Introduction}

Noise from traffic and other sources produces severe problems for people in urban environments. Recent studies have reported that the major source of noise is traffic and exposure to such noise causes annoyance and speech interference in urban areas $[1,2]$. Therefore, research has been conducted to reduce urban noises. Noise barriers are commonly used, and green roofs and building façades treatments have also been explored [3, 4]. Using the concept of soundscapes [5-7], various types of natural sounds such as water sounds and bird songs have also been introduced to mask traffic noise.

Another problem is noise propagation in urban environments enclosed by tall buildings. Calculation methods for predicting the sound fields of urban areas are determined according to the acoustical characteristics of the street boundaries. Image source and ray tracing method have been used for fundamental analysis of urban areas with perfectly smooth and geometrically reflective façades [8-12]. A number of methods have also been developed for façades with irregularities that produce diffuse reflections [4, 13-17]. In particular, the recent study [17] examined the relationship between scattering and the acoustic characteristics of urban street. Commercial software packages such as Raynoise and ODEON were employed too to examine sound propagation in urban areas with irregular surfaces $[1,18]$.

Previous studies on sound propagation in urban areas have mainly focused on street canyons [4, 9-17], although few studies have also investigated urban squares $[1,18]$. A street canyon is a basic urban unit that can be found throughout urban areas. A street canyon comprises a combination of horizontal and vertical surfaces and therefore, the ratio of building height to street width determines how enclosed a street is perceived for people using it [19]. In order to make people feel more comfortable and secure in a 
street canyon, urban design studies have suggested ideal height-to-width ratios (H/W) of $1: 2$ to $1: 1$ [20], $2: 1$ to $2.5: 1$ [21], and $1: 1[19,22]$. Jacobs [23] also described that the proportion of building height to street width should be at least 1:2. Several studies have investigated the relationship between the perception of urban street and $\mathrm{H} / \mathrm{W}$ in relation to safety and comfort in street canyons [24, 25], and Alexander et al. [22] reported that the width of a street should not be greater than the building heights in order to maintain a comfortable feeling of enclosure.

Designing urban street has been a major issue in a global approach for an environmental urban design. In particular, the influences of the street design on urban microclimate have been investigated with highlighting the impacts of $\mathrm{H} / \mathrm{W}$ because $\mathrm{H} / \mathrm{W}$ is the most relevant parameter on street geometry [26-28]. In environment urban design studies, street canyons were characterized in terms of $\mathrm{H} / \mathrm{W}$; shallow canyon with $\mathrm{H} / \mathrm{W}$ below 0.5 , uniform canyon with $\mathrm{H} / \mathrm{W}$ of 1 , and deep canyon with $\mathrm{H} / \mathrm{W}$ more than 2 [29]. In addition, $\mathrm{H} / \mathrm{W}$ was found to directly affect the urban microclimate such thermal comfort and temperature at street level [26, 27].

Although the height-to-width ratio in street canyons has been widely investigated in architecture, urban planning, and urban environment, there has only been limited research about the influence of $\mathrm{H} / \mathrm{W}$ on sound propagation in street canyons. Kang [15] examined the $\mathrm{H} / \mathrm{W}$ of $0.3,0.9$, and 1.5 with a fixed width $(20 \mathrm{~m})$ and varying street heights $(6,18,30 \mathrm{~m})$ in street canyons. Kang [16] also dealt with sound propagation in the interconnected streets but the range of the H/W was limited: 1) H/W of 2.0 and 0.5 with varying street widths (10 m and $40 \mathrm{~m}$ ) and constant building height (20 m) and, 2) H/W of 1.0 and 3.0 with combinations of a fixed street width $(20 \mathrm{~m})$ and varying building heights (20 m and $60 \mathrm{~m}$ ). Onaga and Rindel [17] also investigated the H/W of 
$0.3,0.9$, and 1.5 but the width of the street was fixed at $20 \mathrm{~m}$. The range of $\mathrm{H} / \mathrm{W}$ and the combinations of street width and building height used in these studies [15-17] are insufficient to cover the full range and urban settings that can be found in real urban areas. This is mainly because previous studies focused on the influences of boundary reflection pattern on sound propagation with limited numbers of urban streets. Therefore, it is important to systematically investigate the influence of $\mathrm{H} / \mathrm{W}$ on sound propagation in the street canyons in order to get an overview of the sound propagation in streets with wide range of $\mathrm{H} / \mathrm{W}$.

The H/W and cross-section ratio of enclosed spaces significantly influences sound fields, in particular lateral reflection [30]. If the height and width increase, the level of lateral reflections will decrease relative to the direct sound, and the ratio of lateral to non-lateral sound will also fall [31]. Therefore, a smaller width produces stronger lateral reflections, and thus leads to better spatial impression in auditoriums. It seems likely that the significance of $\mathrm{H} / \mathrm{W}$ can also be found in street canyons. Similar to enclosed spaces, a street canyon is surrounded by reflective building façades and the distance between the buildings and building heights has an impact on the amount of lateral reflections, which can be interpreted by acoustic parameters such as sound pressure level (SPL) and reverberation time (RT).

In this paper, therefore, the propagation of sound in urban streets is investigated with a range of $\mathrm{H} / \mathrm{W}$. The purpose of this study is to provide an overview of the sound fields in narrow and wide urban streets with a large variation of H/W. It was expected that the reflected sounds from building façades would play a significant role in the sound fields in urban streets and the acoustical characteristics of street canyon would be different according to $\mathrm{H} / \mathrm{W}$. The sound fields were predicted using a software package 
based on image source method and ray tracing technique. Computer simulations were validated by comparisons with experimental studies [32, 33]. Sound pressure level and reverberation time were then obtained from the simulations while $\mathrm{H} / \mathrm{W}$ varies from 0.5 to 6. Moreover, the influences of the scattering coefficients of the façades were examined.

\section{Method}

Using computer simulation, a parametric study was carried out in a number of idealized street canyons in order to systematically explore the influence of $\mathrm{H} / \mathrm{W}$ on the sound fields. The H/W was varied at street widths of $6 \mathrm{~m}, 13 \mathrm{~m}, 20 \mathrm{~m}$, and $27 \mathrm{~m}$, representing narrow to wide streets.

\subsection{Simulation model}

The configuration used in this study is shown in Figure 1. Similar to a previous study [15], the buildings were continuous along a street at constant heights. The street length was $200 \mathrm{~m}$ so that sound propagation is not affected by the street length, in the source-receiver range considered. Nelessen recommended widths for urban streets as 6 m (20 ft) for alleys, $19.5 \mathrm{~m}(64 \mathrm{ft})$ for a main street, and $26.2 \mathrm{~m}(86 \mathrm{ft})$ for a boulevard [20]. In addition, an examination of major cities revealed that the maximum widths of major urban streets in Rome, Los Angeles, and Baghdad are around $26 \mathrm{~m}$ that corresponds to the width for the main street as suggested by Nelessen [20]. Therefore, as illustrated in Figure 1(b), the canyon widths varied from $6 \mathrm{~m}$ to $27 \mathrm{~m}$ in order to fully cover the range of widths of urban streets from narrow street $(6 \mathrm{~m})$ to wide street $(27 \mathrm{~m})$. Omnidirectional point sources were located around the middle of urban streets: 1) $x=30$ 
$\mathrm{m}, y=2 \mathrm{~m}$ for width of $6 \mathrm{~m}, 2) x=30 \mathrm{~m}, y=3.9 \mathrm{~m}$ for width of $13 \mathrm{~m}, 3) x=30 \mathrm{~m}, y=6 \mathrm{~m}$ for width of $20 \mathrm{~m}$, and 4) $x=30 \mathrm{~m}, y=8.5 \mathrm{~m}$ for width of $27 \mathrm{~m}$. Thirteen receivers simulating walking pedestrians on sidewalks were located in the range of $x=31 \mathrm{~m}$ and $x=90 \mathrm{~m}$ along a direction length. The distances from the nearest building façade to receivers in $y$ direction were different, namely $1 \mathrm{~m}$ for the street width of $6 \mathrm{~m}, 1.5 \mathrm{~m}$ for width of $14 \mathrm{~m}$, and $2 \mathrm{~m}$ for widths of $20 \mathrm{~m}$ and $27 \mathrm{~m}$, because it was assumed that the width of the sidewalk would be changed according to the width of urban street. The source-receiver distance along the length was 1-60 $\mathrm{m}$ in terms of the horizontal distance along the street length. The heights of the point source and receivers were $1.0 \mathrm{~m}$ and 1.5 m, respectively.

\section{Figure 1}

As listed in Table 1, the heights of the buildings were changed when the widths of an urban street were fixed to $6 \mathrm{~m}, 13 \mathrm{~m}, 20 \mathrm{~m}$, and $27 \mathrm{~m}$. It was assumed that the minimum height of buildings is $3 \mathrm{~m}$, which corresponds to the standard height from floor to next floor. The maximum values of the building heights were $36 \mathrm{~m}$ and $162 \mathrm{~m}$ for narrow and wide streets, respectively. Therefore, the height-to-width ratio (H/W) varied in seven steps from 0.5 to 6 , and this range was much larger than the $0.3-1.5$ of $\mathrm{H} / \mathrm{W}$ considered in the previous studies $[15,17]$ with a fixed width of $20 \mathrm{~m}$. In addition, a total number of streets examined in the present study is 28 , which is much larger than the cases considered in the previous studies [15-17]. 
The ground was assumed to be smooth and hard and therefore, the absorption and scattering coefficients of the ground were both 0.1 [15]. All the vertical planes (façades) were also assumed to have an absorption coefficient of 0.1 . A previous study suggested a scattering coefficient of 0.09-0.13 for façades with surface irregularities [34]. However, a recent study reported that typical façades behave more likely as diffuse reflectors for the most dominant frequency components [35]. This result implies that the scattering coefficient of the building façades would be larger than 0.1. It is also suggested in ODEON that the scattering coefficient would be about 0.4-0.5 for rough building structures with a depth of 0.3-0.5 $\mathrm{m}$ [36]. Therefore, in the present study, a scattering coefficient of 0.3 was applied to the building façades in the simulation. The ceiling (open sky) was completely absorbent.

\subsection{Simulation method}

Acoustics software package ODEON version 12.0 was used to model typical urban streets. For point sources, a hybrid calculation method combining the image source method for low order reflections with a ray tracing method for the late part of the response was used [36]. Simulations were performed by setting the transition order $(\mathrm{TO})=2$, by using 50000 rays and a reflection order of 2000. Impulse response lengths were fixed at $4000 \mathrm{~ms}$ throughout the simulation.

\subsection{Acoustical parameters}

Previous studies [15-18] focused on sound attenuation and reverberation in urban streets in terms of steady-state sound pressure level (SPL), reverberation time (T30), 
and early decay time (EDT). Correspondingly, SPL, T30, and EDT were also analysed in the present study. Only the results at $1 \mathrm{kHz}$ were presented because the absorptions of the facades were uniform over the frequency range.

\subsection{Validation of the computer simulation}

For validation of the computer simulation, predicted results obtained from the computer simulation were compared with results from previously reported experimental studies [32, 33]. Picaut et al. [32] performed an experimental study of sound propagation in a street with H/W of 2.3 (18 m height and $7.9 \mathrm{~m}$ width), which can be compared with the simulated street with a H/W of 2.0 (width: $6.0 \mathrm{~m}$ ) in this study. They used a piston as a point sound source and considered four measurement configurations (S1-S4) with different source and receiver positions. For the S3 where the sound source was located at the beginning of the street and $0.52 \mathrm{~m}$ above the pavement, the SPL at 1 $\mathrm{kHz}$ for receivers with a height of $1.2 \mathrm{~m}$ was attenuated by $11.5 \mathrm{~dB}$, while the sourcereceiver distance varied from $6 \mathrm{~m}$ to $50 \mathrm{~m}$. Figure 2(a) shows the relative SPLs with reference to the SPL at $6 \mathrm{~m}$ from the source and it was observed that predicted results show a good agreement with the experiments. The SPL decreases at $50 \mathrm{~m}$ for simulation and experiment were $-11.5 \mathrm{~dB}$ and $-12.6 \mathrm{~dB}$, respectively. As shown in Figure 2(b), the reverberation times from the computer simulation are also in accordance with those of the experimental study. The measured T30 for S3 at $1 \mathrm{kHz}$ was almost constant with only very small fluctuations from 1.2 to $1.4 \mathrm{~s}$, while the T30 at $1 \mathrm{kHz}$ predicted from the simulation ranged from 1.1 to $1.4 \mathrm{~s}$.

Figure 2 
Figure 3 represents the SPL, RT, and EDT for simulated street with a H/W of 2.0 (width: $6.0 \mathrm{~m}$ ) while the number of rays varied from 1000 to 500000 . The relative SPLs with reference to the SPL at $1 \mathrm{~m}$ from the source are not influenced by increase of number of rays, and all the results are consistent with experimental data. However, the RT and EDT are slightly scattered at several locations compared with experimental data when number of rays are 1000 and 10000. The predictions of RT and EDT become stable when number of rays is greater than 50000 .

\section{Figure 3}

A similar experimental study was conducted by Picaut and Simon [33] in the street with a H/W of 0.7 (8 $\mathrm{m}$ height and $12 \mathrm{~m}$ width), and this can be approximately compared with the simulated street with a $\mathrm{H} / \mathrm{W}$ of 0.5 (13 m width). In the experimental study, a sound source was located at the beginning of the street where the sourcereceiver distance ranged from $2 \mathrm{~m}$ to $96 \mathrm{~m}$. Measured results were reported for the SPL and reverberation time at $630 \mathrm{~Hz}$ and $2 \mathrm{kHz}$; however, only measured results at $2 \mathrm{kHz}$ were comparable with the simulation because ODEON provides the prediction results in 1/1 octave band. In general, good agreement was observed for both the SPL and reverberation time. The SPL decrease at $64 \mathrm{~m}$ was around $18 \mathrm{~dB}$ in the experimental study, and the predicted SPL decreased by around $17 \mathrm{~dB}$ in the similar distance (2 m-60 m). The reverberation times in the experimental study were similar to those of the simulation in the near field with less than $1.0 \mathrm{~s}$. The measured reverberation time was around $1.5 \mathrm{~s}$ in the far field, whereas the simulated T30 was less than $1.3 \mathrm{~s}$. These 
results represent the computer simulation is reliable. Therefore, in the rest of this paper, the effects of $\mathrm{H} / \mathrm{W}$ on sound fields were investigated based on computer simulations.

\section{Results and discussions}

\subsection{Sound attenuation along the length}

Figure 4 shows comparisons between different $\mathrm{H} / \mathrm{W}$ in the sound attenuation along the length, with reference to the SPL at $1 \mathrm{~m}$ from the source, with four street widths. The results correspond to the findings of Kang [15] based on a radiosity model, namely, higher building façades result in less sound attenuation along the length due to the reflection from façades, and the sound attenuation curves are concave, indicating that the sound attenuation becomes less with the increase of source-receiver distance.

\section{Figure 4}

However, significant differences between widths were also found. The SPL at $x=1$ $\mathrm{m}$ for the $6 \mathrm{~m}$ width is greater than the SPL at $x=1 \mathrm{~m}$ with other widths. This is because the actual distances between the source and receiver at $x=1 \mathrm{~m}$ for other widths are much larger than that with a width of $6 \mathrm{~m}$, resulting in a decrease in direct sound energy. For the width of $6 \mathrm{~m}$, the SPL attenuation becomes significantly less when H/W is increased from 0.5 to 2 but H/W does not significantly affect the SPL attenuation with H/W $>2$. The influence of H/W on the SPL attenuation is more significant in the far field than in the near field. As shown in Figures 4(b), 2(c), and 2(d), differences between different $\mathrm{H} / \mathrm{W}$ decrease with the increase in street width. For widths of $13 \mathrm{~m}$ and $20 \mathrm{~m}$, sound pressure levels for $\mathrm{H} / \mathrm{W}$ of 0.5 and 1 are less than those for other $\mathrm{H} / \mathrm{W}$ but the ranges of 
the sound pressure levels for $\mathrm{H} / \mathrm{W}$ at same receiver positions are much smaller than that for the width of $6 \mathrm{~m}$. In particular, with the width of $27 \mathrm{~m}$, there is no significant difference between different H/W. Overall, those results suggest that the influence of $\mathrm{H} / \mathrm{W}$ on sound propagation is significant only in the range of $\mathrm{H} / \mathrm{W}=0.5-2$, and in the meantime, the influence becomes less with the increase in street width. In other words, the increase of building height does not contribute significantly to the SPL in the streets with a large width.

Differences between narrow and wide urban streets also can be explained by analysing sound pressure levels of direct sound, specular reflections, and scattered sounds. As shown in Figure 5(a), for width of $6 \mathrm{~m}$, the dominant reflection is specular reflection in the near field, within about $10 \mathrm{~m}$ from the source, whereas the scattering reflection is dominant in the far field. The contribution of the specular reflection to the total sound energy in the near field decreases as $\mathrm{H} / \mathrm{W}$ increases, particularly $\mathrm{H} / \mathrm{W}$ varies from 0.5 to 2 . This is because the scattering sound quickly absorbed by open sky $(100 \%$ absorbent) in urban streets with low $\mathrm{H} / \mathrm{W}$ [17], and scattering energies increase as $\mathrm{H} / \mathrm{W}$ increases. It is also observed that the increase of the scattering energy is significant in the far field. Onaga and Rindel [17] examined the urban streets (width: $20 \mathrm{~m}$ ) with different $\mathrm{H} / \mathrm{Ws}(0.3,0.6$, and 1.5$)$ and reported the specular and scattering reflection energies while the direct sound was included in the specular reflection. They demonstrated that the specular and scattering reflections are dominant in low and highfaçade streets, respectively. Similar streets with same width (presented in Figure 5(c)) showed similar tendency in the far field. The specular reflection is dominant in the street with $\mathrm{H} / \mathrm{W}$ of 0.5 and the scattering reflection becomes larger as $\mathrm{H} / \mathrm{W}$ increases. For width of $27 \mathrm{~m}$, the specular reflection is dominant at most receivers except for very 
far field, beyond about $40 \mathrm{~m}$ from the source. In addition, the scattering energy is almost constant along the length and the increase of the scattering with increasing $\mathrm{H} / \mathrm{W}$ is smaller than urban street width of $6 \mathrm{~m}$. This represents the tall building facades do not lead to the increase of scattering reflections from the facades in wide urban street.

Figure 5

\subsection{Reverberation time (T30)}

Predicted reverberation time (T30) is shown in Figure 6. The results show similar tendencies to the results with diffusely reflecting boundaries reported by Kang [15]. With widths of $6 \mathrm{~m}$ and $13 \mathrm{~m}$, the T30 is almost constant with increasing sourcereceiver distance, whereas the T30 slightly increases along the source-receiver distance for widths of $20 \mathrm{~m}$ and $27 \mathrm{~m}$. The T30 for the width of $6 \mathrm{~m}$ are less than $2.0 \mathrm{~s}$, while the maximum T30 gradually increases up to around $7.0 \mathrm{~s}$ for the width of $27 \mathrm{~m}$. This can be explained by differences in the volume of the street canyon. With a fixed H/W, the T30 are much longer with a greater width because the street volume is significantly increased. Another reason of long reverberation times may be attributed absorption coefficient. Onaga and Rindel [17] reported that the apparent absorption coefficient of a street canyon (width: $12 \mathrm{~m}$ and height: $8 \mathrm{~m}$ ) is between 0.15 and 0.2, and Forssén et al. also [43] used absorption coefficient of 0.2 for façade in urban canyon situations. In contrast, the absorption coefficients of facades are fixed at 0.1 in the present study, since the purpose is to examine more uniformly distributed building with reflective facades so that the canyon effects are more obvious. As expected, the T30 becomes longer with the increase of building height for all widths. However, the increase in T30 becomes less 
with a relatively high H/W. For example, for the width of $27 \mathrm{~m}$, the difference between H/W of 5 and 6 is less than $9 \%$, as can be seen in Figure 6(d).

\section{Figure 6}

\subsection{Early decay time (EDT)}

Figure 7 shows the early decay time for the urban streets with four different widths. Overall, the EDT increases along the source-receiver distance in each street, which is in agreement with a previous study [15]. With the width of $6 \mathrm{~m}$, the EDT rapidly increases in the near field, within about $10 \mathrm{~m}$ from the source, and becomes relatively steady in the far field. The EDT increases with the increase of $\mathrm{H} / \mathrm{W}$, but the increase is insignificant with about $\mathrm{H} / \mathrm{W}>4$.

\section{Figure 7}

Similar to the T30 results, the EDT becomes longer with increased street width, due to the increase in the volume between buildings. For the width of $6 \mathrm{~m}$, the longest EDT is less than $2.0 \mathrm{~s}$ in the far field, whereas with the width of $27 \mathrm{~m}$ the longest EDT is more than $5.0 \mathrm{~s}$. Compared with the width of $6 \mathrm{~m}$, other widths show slightly different tendencies with increasing H/W. For smaller H/W, the EDT quickly increases in the near field and then becomes relatively even in the far field, whereas for larger H/W, the EDT continuously increases even in the far field. For instance, the EDT for the width of $27 \mathrm{~m}$ almost increases linearly along the length when the $\mathrm{H} / \mathrm{W}$ is greater than 3 . The results also show that a larger H/W produce a longer EDT in each street canyon. The influence 
of $\mathrm{H} / \mathrm{W}$ on the EDT is significant when $\mathrm{H} / \mathrm{W}$ is small, and the EDT increase becomes less with a relatively high H/W. For widths of $20 \mathrm{~m}$ and $27 \mathrm{~m}$, it is interesting to note that the EDT at $x=4$ is around $0.1 \mathrm{~s}$ for all H/W cases even though the T30 at the same positions are more than $2.0 \mathrm{~s}$. This is because the direct and first reflected sounds are dominant, and the reflected sound from the opposite façades only arrives after $80 \mathrm{~ms}$.

Figure 8 shows reverse integrated sound level decay curves at distances of $10 \mathrm{~m}$ and $35 \mathrm{~m}$ from the source representing the near and far fields, respectively. The initial shapes of the curves are slightly different according to the receiver position. The decay curves in the near field are 'cliff-type' decays because the direct sound and the specular reflections are dominant [37]. Therefore, the EDTs in the near field are shorter than the T30s, particularly for widths of $20 \mathrm{~m}$ and $27 \mathrm{~m}$. In contrast, the decay curves in the far field could be classified into 'plateau type' decay indicating that the scattering reflection is more dominant rather than the early (specular) reflection. The T30 is longer than the EDT in the far field but the differences between them are much smaller than those in the near field.

Figure 8

\subsection{Line source}

In the above sections, omnidirectional point sources were used to understand sound propagation in street canyons with different H/W. However, road traffic noise, the most common noise source in urban streets, has generally been considered to be an incoherent line source [38-41]. Therefore, additional computer simulations were performed using line sources for streets with widths of $6 \mathrm{~m}$ and $27 \mathrm{~m}$. The SPL, T30, 
and EDT for two widths are plotted in Figure 9. As expected, with the point source, the SPL decreased linearly along the length, whereas the SPLs are almost constant for both widths with the line source. It is interesting to note that similar tendencies were found in the results of EDT. The EDT of two streets is found to be relatively constant with a line source. The average values of EDT obtained from the setting with a line source are similar to those for far field in simulations with a point source. However, T30 is not influenced by change of sound source type. For both streets with different widths, T30 is steady along the length. Additional analysis for quantifying the direct, specular and scattering reflections is not available in the present study because transition order is always zero and only late energy contributions are calculated for a line source in ODEON [36].

Figure 9

\subsection{Boundary reflection pattern}

Irregularly shaped façades produce different sound fields compared with geometrically reflecting boundaries $[17,18]$. Therefore, conditions in between partially diffuse and partially geometrical boundaries were investigated, with the scattering coefficients varied from 0.1 to 0.9 with an interval of 0.2 . Three cases with $\mathrm{H} / \mathrm{W}$ of 0.5 , 3 , and 6 were selected among the seven H/W cases used in the previous sections for widths of $6 \mathrm{~m}$ and $27 \mathrm{~m}$. Three receivers located at $x=10 \mathrm{~m}, 30 \mathrm{~m}$, and $50 \mathrm{~m}$ were chosen in order to investigate the near, middle, and far fields.

Variations in SPL, T30, and EDT with increasing scattering coefficient ranging from 0.1 to 0.9 are illustrated in Figure 10 for the width of $6 \mathrm{~m}$. The SPL at three 
receiver positions are almost steady for all $\mathrm{H} / \mathrm{W}$ cases. This confirms the previous finding of Onaga and Rindel [17] reporting that the sound pressure levels are rarely affected by the change of scattering coefficients. However, the T30 and EDT show different tendencies according to the change of $\mathrm{H} / \mathrm{W}$. For a $\mathrm{H} / \mathrm{W}$ of 0.5 , the T30 decreases when the scattering coefficient increases from 0.1 to 0.3 , and then the changes in T30 decreases when the scattering coefficient further increases. On the other hand, the T30 slightly decreases with an increase in scattering coefficient for $\mathrm{H} / \mathrm{W}$ of 3 , while the T30 is almost constant when the scattering coefficient increases from 0.1 to 0.9 for $\mathrm{H} / \mathrm{W}$ of 6 . The variations in the EDT are also different according to H/W. For H/W of 0.5, the EDT slightly decreases when the scattering coefficient increases from 0.1 to 0.3 but the change is insignificant when the scattering coefficient is greater than 0.3. However, the tendencies for the H/W of 3 and 6 are opposite to those with the H/W of 0.5. The EDT increases with scattering coefficients below 0.5 and then, turns to be approximately constant with scattering coefficients above 0.5 .

Figure 10

Figure 11 shows the variations in SPL, T30, and EDT for the width of $27 \mathrm{~m}$. The overall tendencies for SPL, T30, and EDT with changing H/W are similar to those for the width of $6 \mathrm{~m}$. The SPL is little influenced by the scattering coefficient as well as H/W, whereas the T30 and EDT are significantly influenced with changing scattering coefficient. For the T30, the differences between the three receiver positions are significant with low scattering coefficients such as 0.1 and 0.3 , whereas for the EDT, the differences between the receiver positions becomes greater with increasing $H / W$. 
Previous studies $[17,42]$ also reported that the reverberation time is almost constant in the range of scattering coefficients from 0.2 to 1 for urban streets with $\mathrm{H} / \mathrm{W}$ of $0.3,0.9$, and 1.5 (width: $20 \mathrm{~m}$ ).

\section{Figure 11}

\section{Conclusions}

Effect of height-to-width ratio (H/W) on the sound propagation in urban streets has been systematically investigated through computer simulation. Acoustical results of the present study are validated by comparing with those of experimental studies, and it is found that the differences between simulation and measurement are less than $15 \%$ in both sound pressure level and reverberation time. Considerable differences between street widths have been observed in SPL. For a width of $6 \mathrm{~m}, \mathrm{H} / \mathrm{W}$ results in a significant change in SPL, especially in the far field. A larger H/W leads to less sound attenuation along the length, by about $8 \mathrm{~dB}$ with a source-receiver distance of $36 \mathrm{~m}$. However, the influence of H/W on the SPL gradually becomes less, while street width is increased from $6 \mathrm{~m}$ to $27 \mathrm{~m}$. For the widest street of $27 \mathrm{~m}$, only $1.2 \mathrm{~dB}$ difference between $\mathrm{H} / \mathrm{W}$ has been found at a source-receiver distance of $36 \mathrm{~m}$. The T30 increases with increasing $\mathrm{H} / \mathrm{W}$, typically by $150 \%-300 \%$, but the increase in T30 becomes less with a relatively high $\mathrm{H} / \mathrm{W}$. T30 is almost even along the length for all the street widths studied and a greater street width produces a longer T30. Similar to T30, the EDT also increases as $\mathrm{H} / \mathrm{W}$ increases, by $200 \%-400 \%$ with a source-receiver distance of $36 \mathrm{~m}$, but the change in EDT is not significant for small H/W. The EDT increases along the source-receiver distance in the near field for all street widths, but the variations in the 
far field are slightly different with different street width. The SPL is not influenced by any boundary reflection pattern, but T30 and EDT varied with a change in the scattering coefficients. For a width of $6 \mathrm{~m}$, T30 slightly decreases with increasing scattering coefficient for $\mathrm{H} / \mathrm{W}$ of 0.5 and 3, by $15 \%-40 \%$, but T30 is constant for $\mathrm{H} / \mathrm{W}$ of 6 . The EDT increases by 50\%-200\% for H/W of 3 and 6 with increasing scattering coefficient. For a width of $27 \mathrm{~m}$, the T30 decreases by $20 \%-70 \%$ when the scattering coefficient is increased from 0.1 to 0.9 . The increases of EDT for $\mathrm{H} / \mathrm{W}$ of 3 and 6 are greater than that for $\mathrm{H} / \mathrm{W}$ of 0.5 .

The present study focused on long streets with buildings lined up continuously along both sides; however, there are also other types of street configurations in urban areas such as intersection. Therefore, in the future, additional experiments are needed to extend the knowledge on the influences of height-to-width ratio on sound propagation into a variety of street configurations.

\section{Acknowledgments}

This research was supported by a grant from a Strategic Research Project (A study on noise reduction solution for adjacency household in apartment house) funded by the Korea Institute of Construction Technology. 


\section{References}

[1] P.J. Lee, J.Y. Jeon: Evaluation of speech transmission in open public spaces affected by combined noises, J Acoust Soc Am, 130 (2011) 219-227.

[2] K. Paunović, B. Jakovljević, G. Belojević: Predictors of noise annoyance in noisy and quiet urban streets, Science of the total environment, 407 (2009) 3707-3711.

[3] T. Van Renterghem, D. Botteldooren: Reducing the acoustical façade load from road traffic with green roofs, Building and Environment, 44 (2009) 1081-1087.

[4] D. Hothersall, K. Horoshenkov, S. Mercy: Numerical modelling of the sound field near a tall building with balconies near a road, Journal of Sound and Vibration, 198 (1996) 507-515.

[5] J.Y. Jeon, P.J. Lee, J. You, J. Kang: Acoustical characteristics of water sounds for soundscape enhancement in urban open spaces, J Acoust Soc Am, 131 (2012) 21012109.

[6] B.D. Coensel, S. Vanwetswinkel, D. Botteldooren: Effects of natural sounds on the perception of road traffic noise, The Journal of the Acoustical Society of America, 129 (2011) EL148-EL153.

[7] J. You, P.J. Lee, J.Y. Jeon: Evaluating water sounds to improve the soundscape of urban areas affected by traffic noise, Noise Control Engineering Journal, 58 (2010) 477-483.

[8] F.M. Wiener, C.I. Malme, C.M. Gogos: Sound propagation in urban areas, The Journal of the Acoustical Society of America, 37 (1965) 738-747.

[9] M. Radwan, D. Oldham: The prediction of noise from urban traffic under interrupted flow conditions, Applied Acoustics, 21 (1987) 163-185.

[10] D. Oldham, M. Radwan: Sound propagation in city streets, Building Acoustics, 1 (1994) 65-88.

[11] K. Heutschi: A simple method to evaluate the increase of traffic noise emission level due to buildings, for a long straight street, Applied Acoustics, 44 (1995) 259274.

[12] J. Kang: Reverberation in rectangular long enclosures with geometrically reflecting boundaries, Acta Acustica united with Acustica, 82 (1996) 509-516.

[13] R. Bullen, F. Fricke: Sound propagation in a street, Journal of Sound and Vibration, 46 (1976) 33-42.

[14] K. Heutschi: Computer model for the calculation of the increase of traffic noise immission due to building along a street, Acta Acustica united with Acustica, 81 (1995) 26-35.

[15] J. Kang: Sound propagation in street canyons: Comparison between diffusely and geometrically reflecting boundaries, The Journal of the Acoustical Society of America, 107 (2000) 1394-1404.

[16] J. Kang: Sound propagation in interconnected urban streets: a parametric study, Environment and Planning B, 28 (2001) 281-294.

[17] H. Onaga, J.H. Rindel: Acoustic characteristics of urban streets in relation to scattering caused by building facades, Applied Acoustics, 68 (2007) 310-325.

[18] J. Kang: Numerical modeling of the sound fields in urban squares, The Journal of the Acoustical Society of America, 117 (2005) 3695-3706.

[19] Y. Ashihara: The aesthetic townscape, The MIT Press, Cambridge, 1983.

[20] A.C. Nelessen: Visions for a new American dream: process, principles, and an 
ordinance to plan and design small communities, Planners Press, American Planning Association, 1994.

[21] M. Carmona, S. Tiesdell, T. Heath, T. Oc: Public places Urban spaces: The dimensions of urban design, Architectural Press, Burlington (MA), 2010.

[22] A. Christopher, S. Ishikawa, M. Silverstein: A pattern language: towns, buildings, constructions, Oxford University Press, New York, 1977.

[23] A.B. Jacobs: Great streets, MIT Press, Cambridge (MA), 1993.

[24] S.-B. Im: An investigation of the relationship between visual preference and ratio variables in enclosed urban spaces: An exploration of a scientific approach to environmental design, Ph.D. Thesis, University of Michigan, Ann Arbor, 1983.

[25] M.M. Alkhresheh: Enclosure as a function of height-to-width ratio and scale: Its influence on user's sense of comfort and safety in urban street space, Ph.D. Thesis, University of Florida, 2007.

[26] F. Ali-Toudert, H. Mayer: Numerical study on the effects of aspect ratio and orientation of an urban street canyon on outdoor thermal comfort in hot and dry climate, Building and Environment, 41 (2006) 94-108.

[27] R.A. Memon, D.Y. Leung, C.-H. Liu: Effects of building aspect ratio and wind speed on air temperatures in urban-like street canyons, Building and Environment, 45 (2010) 176-188.

[28] X. Xiaomin, H. Zhen, W. Jiasong: The impact of urban street layout on local atmospheric environment, Building and Environment, 41 (2006) 1352-1363.

[29] K. Ahmad, M. Khare, K. Chaudhry: Wind tunnel simulation studies on dispersion at urban street canyons and intersections-a review, Journal of Wind Engineering and Industrial Aerodynamics, 93 (2005) 697-717.

[30] A.H. Marshall: A note on the importance of room cross-section in concert halls, Journal of Sound and Vibration, 5 (1967) 100-112.

[31] M. Barron: The subjective effects of first reflections in concert halls - the need for lateral reflections, Journal of Sound and Vvibration, 15 (1971) 475-494.

[32] J. Picaut, T. Le Pollès, P. L'Hermite, V. Gary: Experimental study of sound propagation in a street, Applied Acoustics, 66 (2005) 149-173.

[33] J. Picaut, L. Simon: A scale model experiment for the study of sound propagation in urban areas, Applied Acoustics, 62 (2001) 327-340.

[34] M. Ismail, D. Oldham: A scale model investigation of sound reflection from building façades, Applied Acoustics, 66 (2005) 123-147.

[35] K. Heutschi: Incoherence factor as descriptor for the diffusivity of building facades, Acta Acustica united with Acustica, 97 (2011) 933-939.

[36] C.L. Christensen, G. Koutsouris: ODEON Room Acoustics Software: User Manual V12.0 Industrial, Auditorium and Combined Editions, Odeon A/S, Lyngby, Denmark, 2013.

[37] M. Barron: Interpretation of early decay times in concert auditoria, Acta Acustica united with Acustica, 81 (1995) 320-331.

[38] S. Tang: Noise screening effects of balconies on a building facade, The Journal of the Acoustical Society of America, 118 (2005) 213-221.

[39] T. Van Renterghem, E. Salomons, D. Botteldooren: Parameter study of sound propagation between city canyons with a coupled FDTD-PE model, Applied Acoustics, 67 (2006) 487-510.

[40] M. Ogren, W. Kropp: Road traffic noise propagation between two dimensional city 
canyons using an equivalent sources approach, Acta Acustica united with Acustica, 90 (2004) 293-300.

[41] K. Li, K. Iu: Propagation of sound in long enclosures, The Journal of the Acoustical Society of America, 116 (2004) 2759-2770.

[42] J. Kang: Urban sound environment, Taylor \& Francis, London, 2007.

[43] J. Forssén, M. Hornikx, D. Botteldooren, W. Wei, T. Van Renterghem, M. Ögren: A model of sound scattering by atmospheric turbulence for use in noise mapping calculations. Manuscript submitted to Acta Acustica united with Acustica (2013). 
Table 1. Heights of building facades for urban streets with different widths

\begin{tabular}{|cccccccc|}
\hline Width [m] & \multicolumn{7}{c|}{ Height [m] } \\
\hline 6 & 3 & 6 & 12 & 18 & 24 & 30 & 36 \\
\hline 13 & 6.5 & 13 & 26 & 39 & 52 & 65 & 78 \\
\hline 20 & 10 & 20 & 40 & 60 & 80 & 100 & 120 \\
\hline 27 & 13.5 & 27 & 54 & 81 & 108 & 135 & 162 \\
\hline
\end{tabular}




\section{Figure Captions}

Fig. 1. Configurations of urban streets. a) Plan view and b) Cross-section view.

Fig. 2. Simulation and experiment. a) Sound pressure level and b) Reverberation time (T30).

Fig. 3. Sound attenuation, reverberation time (T30), and early decay time (EDT) along urban streets with variations of number of rays.

Fig. 4. Sound attenuations along urban streets. a) Width of $6 \mathrm{~m}, \mathrm{~b}$ ) Width of $13 \mathrm{~m}, \mathrm{c}$ ) Width of $20 \mathrm{~m}$, and d) Width of $27 \mathrm{~m}$.

Fig. 5. Sound pressure levels of direct sound, specular reflections, and scattered sounds.

a) Width of $6 \mathrm{~m}, \mathrm{~b}$ ) Width of $13 \mathrm{~m}, \mathrm{c}$ ) Width of $20 \mathrm{~m}$, and d) Width of $27 \mathrm{~m}$.

Fig. 6. Reverberation time (T30) along urban streets. a) Width of $6 \mathrm{~m}$, b) Width of $13 \mathrm{~m}$, c) Width of $20 \mathrm{~m}$, and d) Width of $27 \mathrm{~m}$.

Fig. 7. Early decay time (EDT) along urban streets. a) Width of $6 \mathrm{~m}$, b) Width of $13 \mathrm{~m}$, c) Width of $20 \mathrm{~m}$, and d) Width of $27 \mathrm{~m}$.

Fig. 8. Reverse integrated sound level decay curves. a) At distance of $10 \mathrm{~m}$ from the source and b) At distance $35 \mathrm{~m}$ from the source.

Fig. 9. Sound attenuation, reverberation time (T30), and early decay time (EDT) along urban streets obtained from the simulations with line source. a) Width of $6 \mathrm{~m}$ and b) Width of $27 \mathrm{~m}$.

Fig. 10. Variation of the SPL, RT, and EDT with increasing scattering coefficient for the width of $6 \mathrm{~m}$ (top: $\mathrm{H} / \mathrm{W}=0.5$, middle: $\mathrm{H} / \mathrm{W}=3$, and bottom: $\mathrm{H} / \mathrm{W}=6$ ).

Fig. 11. Variation of the SPL, RT, and EDT with increasing scattering coefficient for the width of $27 \mathrm{~m}$ (top: $\mathrm{H} / \mathrm{W}=0.5$, middle: $\mathrm{H} / \mathrm{W}=3$, and bottom: $\mathrm{H} / \mathrm{W}=6$ ). 


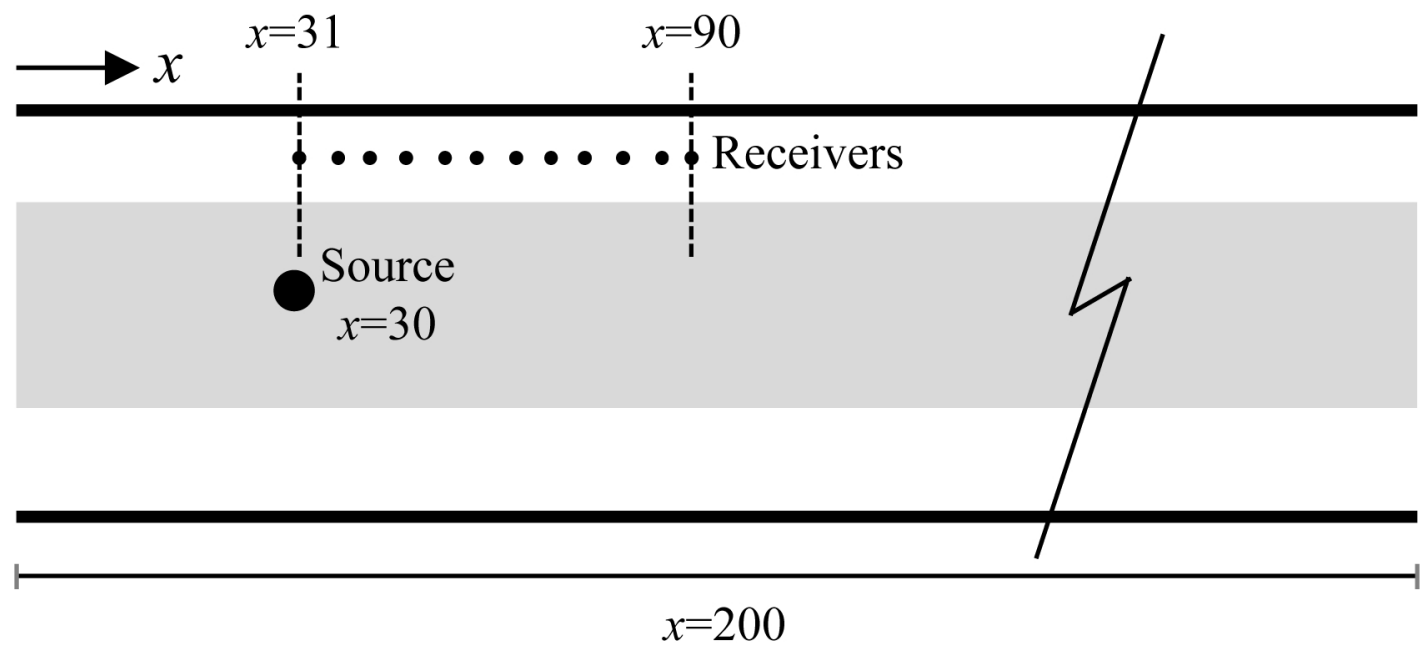

a)

$y=1, z=1.5$ for width of $6 \mathrm{~m}$

$y=1.5, z=1.5$ for width of $13 \mathrm{~m}$

$y=2, z=1.5$ for width of $20 \mathrm{~m}$

$y=2, z=1.5$ for width of $27 \mathrm{~m}$

$z$ Receiver

$\mathrm{y}=2, z=1$ for width of $6 \mathrm{~m}$

Source $\mathrm{y}=3.9, z=1$ for width of $13 \mathrm{~m}$

$\mathrm{y}=6, z=1$ for width of $20 \mathrm{~m}$

- $\mathrm{y}=8.5, z=1$ for width of $27 \mathrm{~m}$

b) 

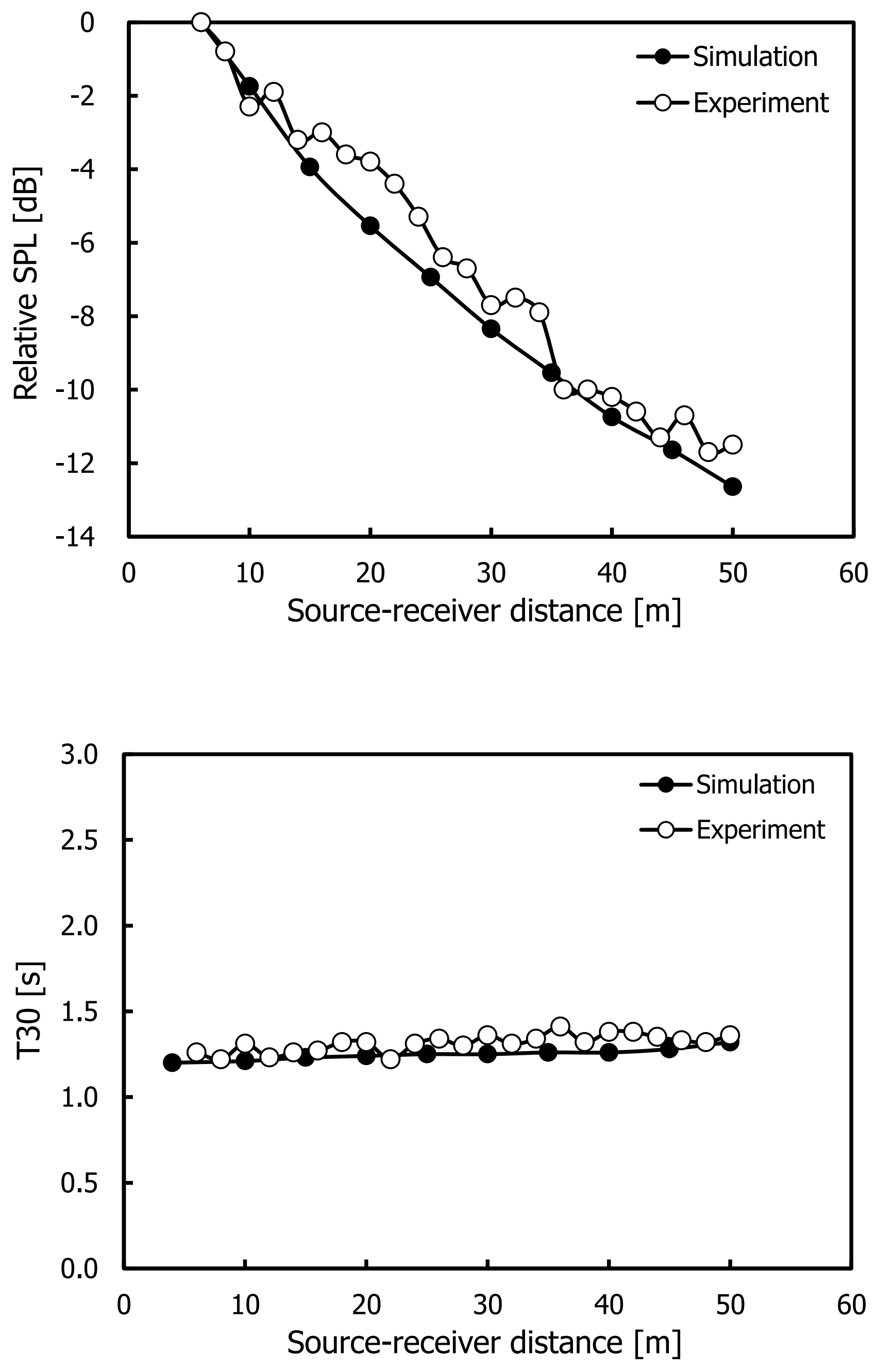

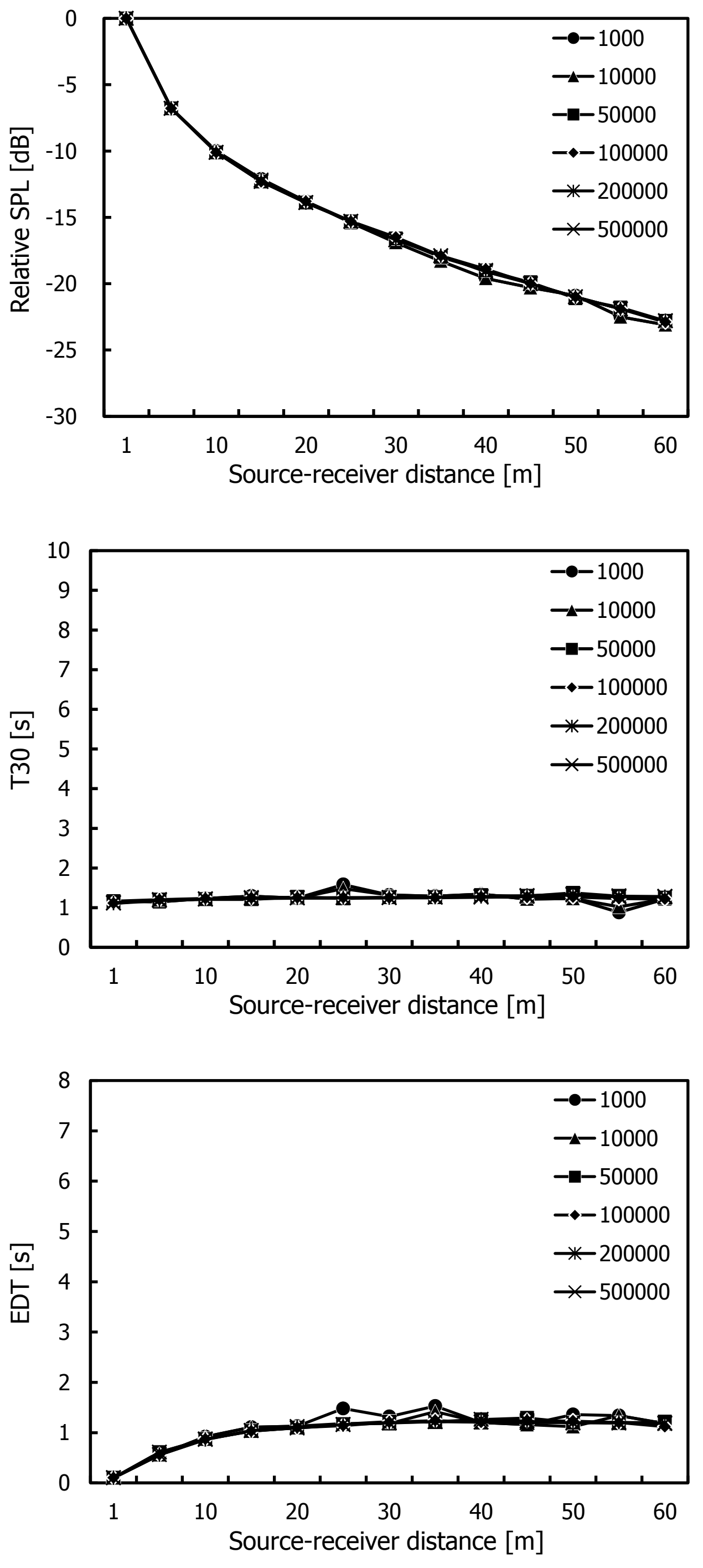


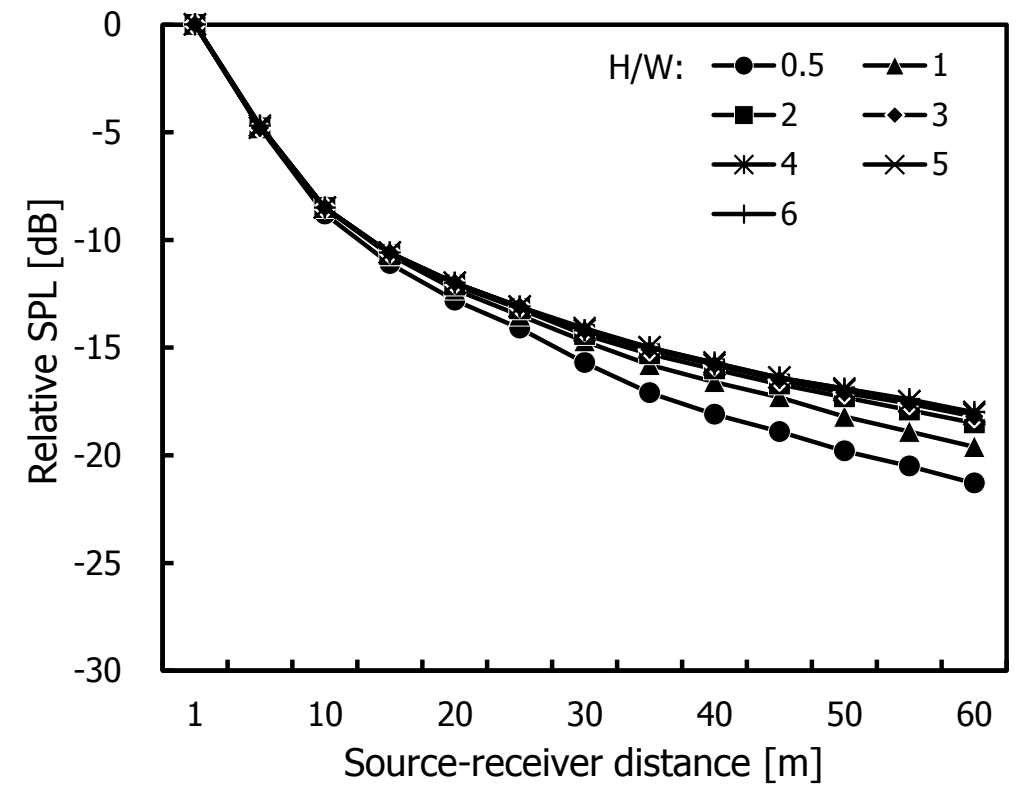

a)

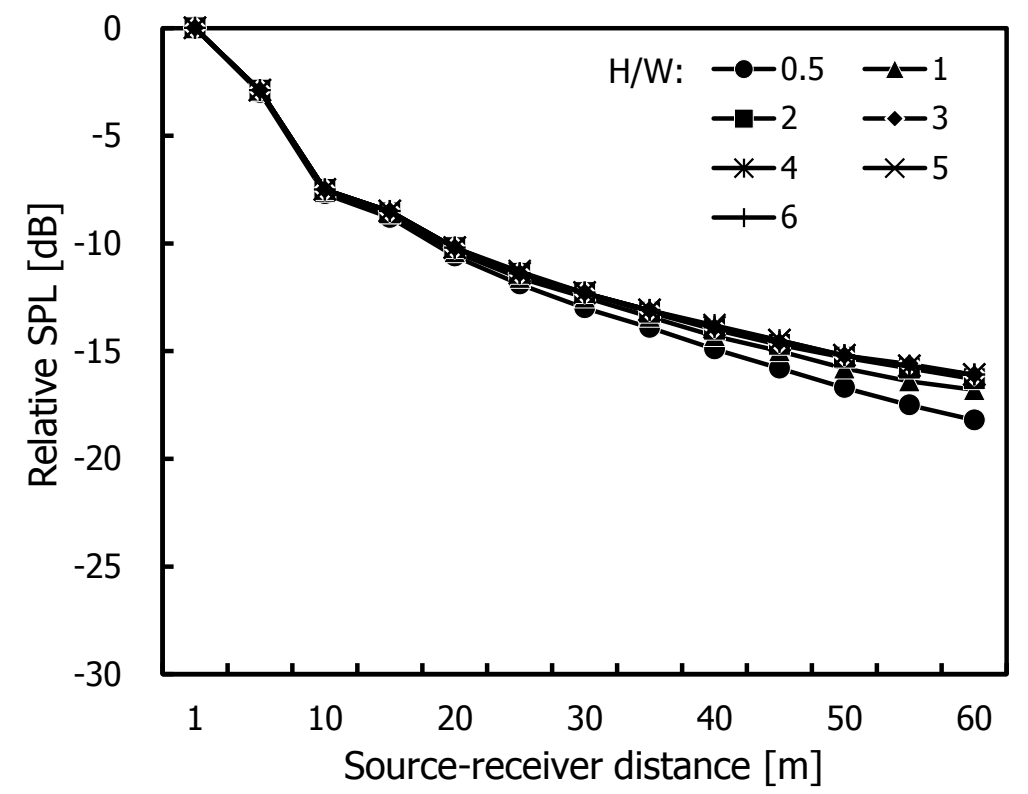

c)

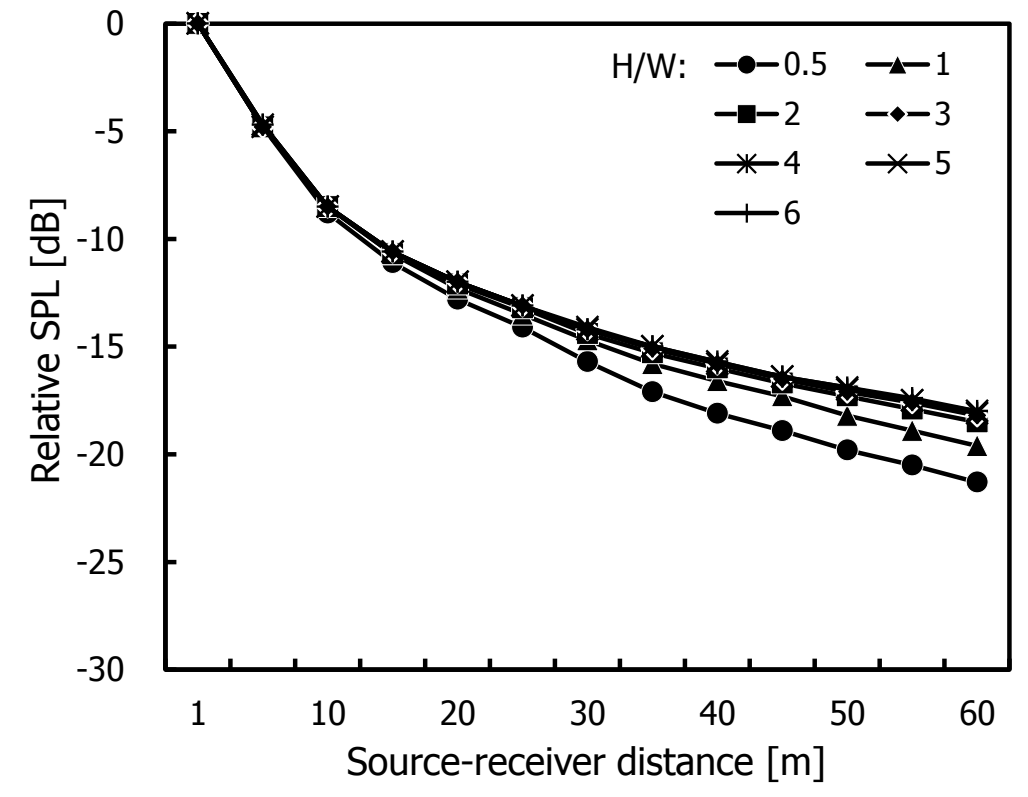

b)

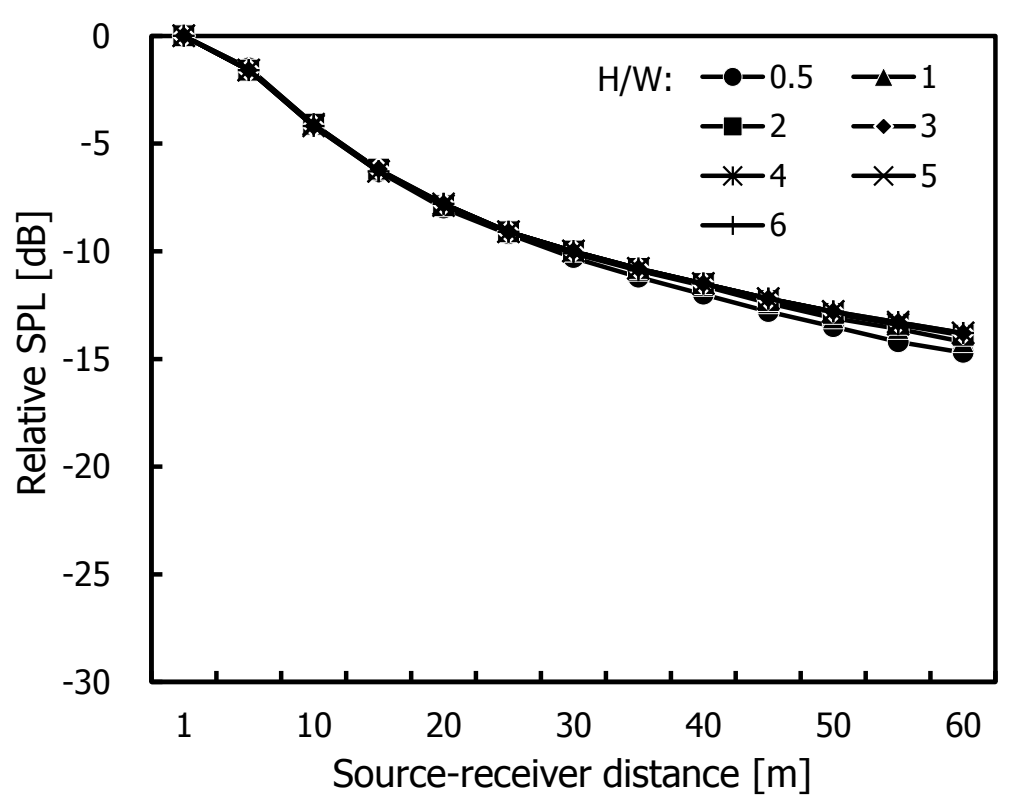

d) 
Figure $5(b)$
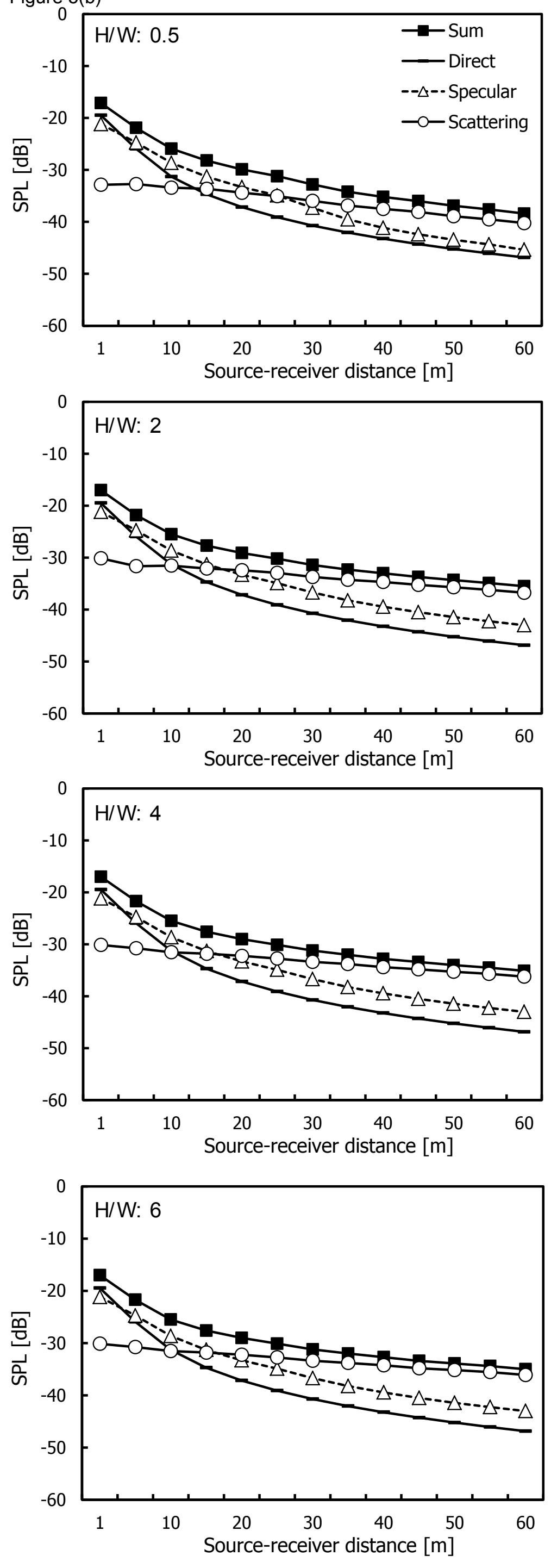
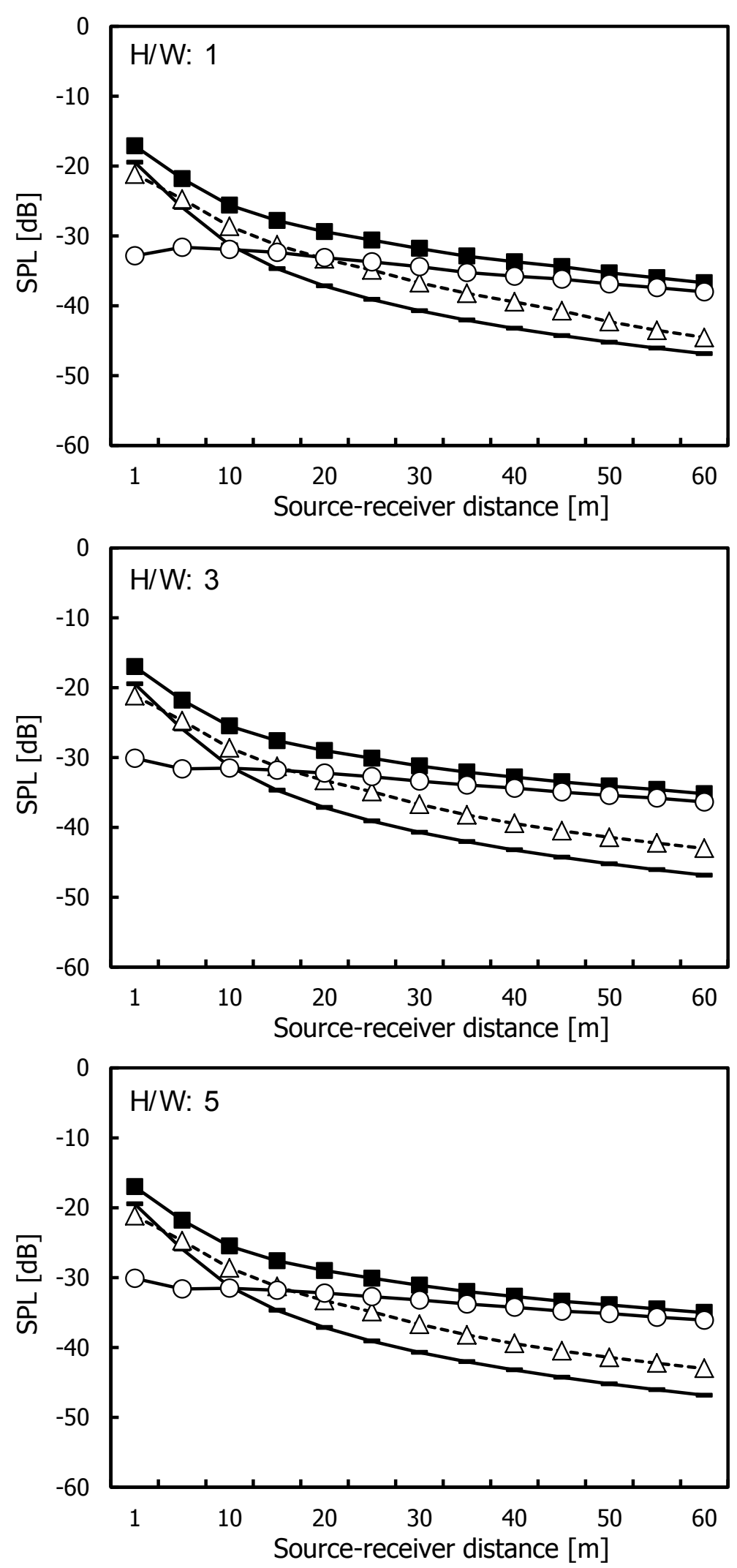


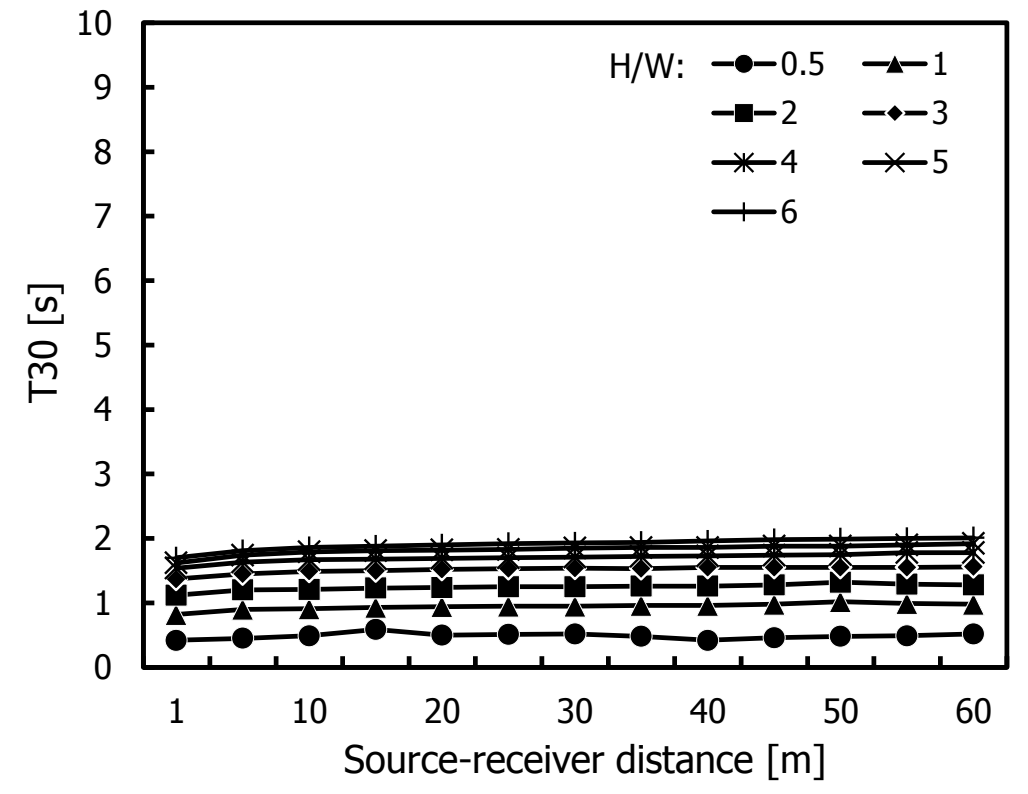

a)

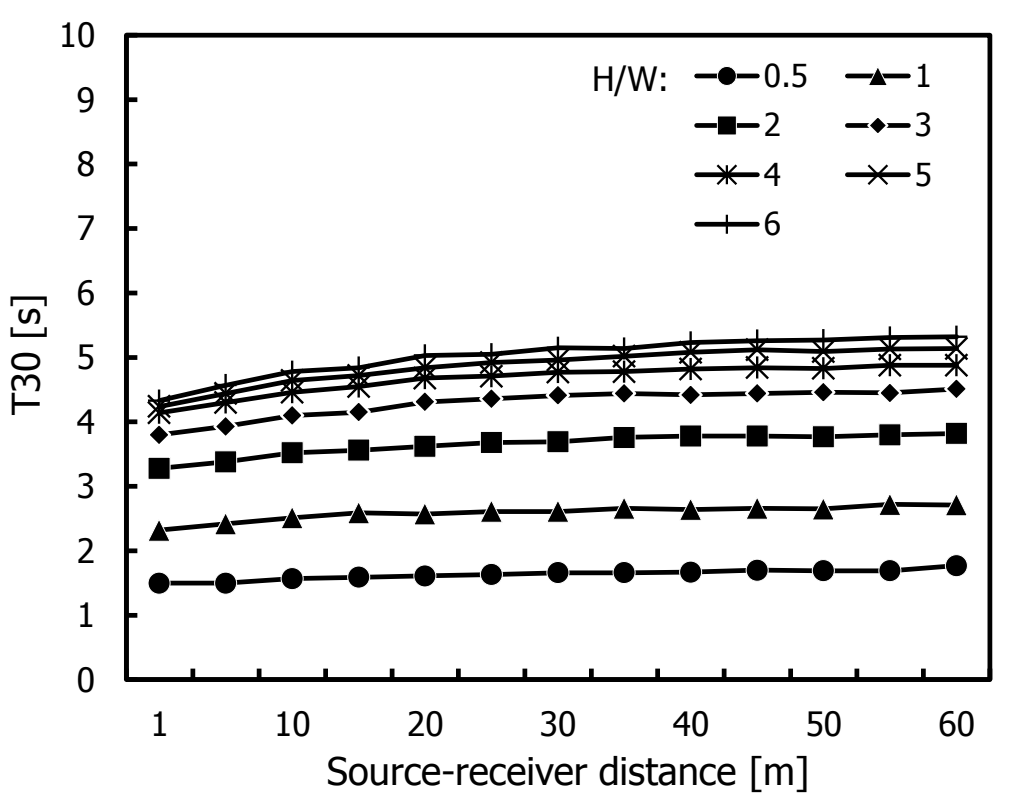

c)

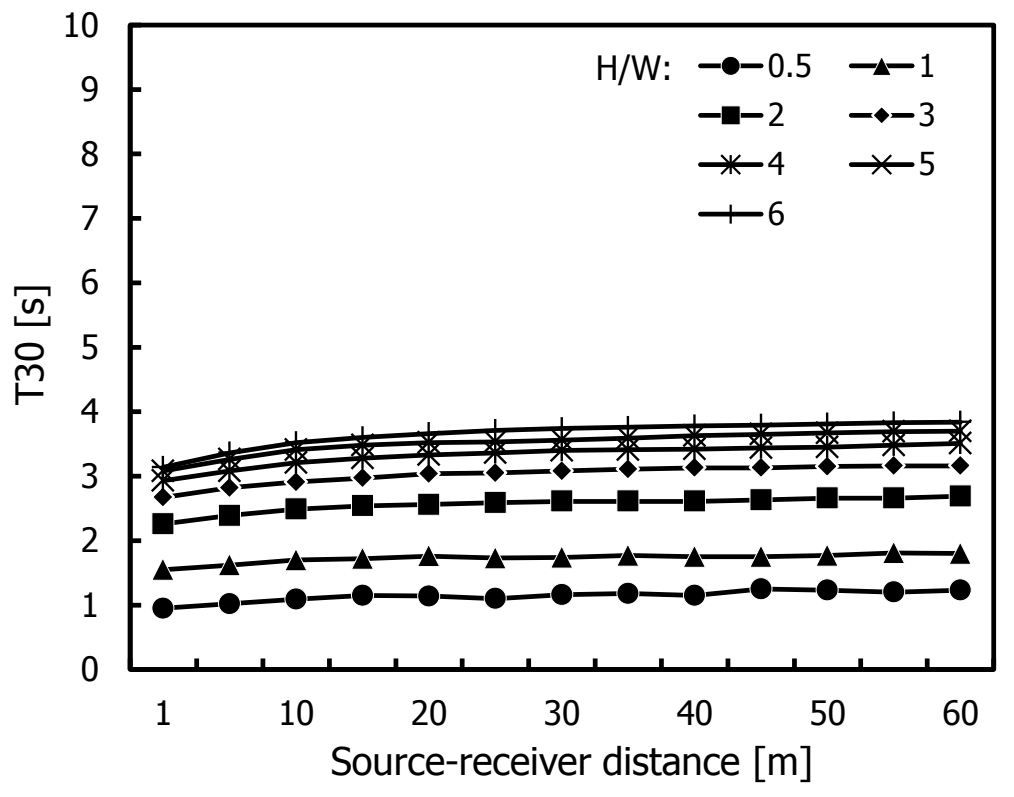

b)

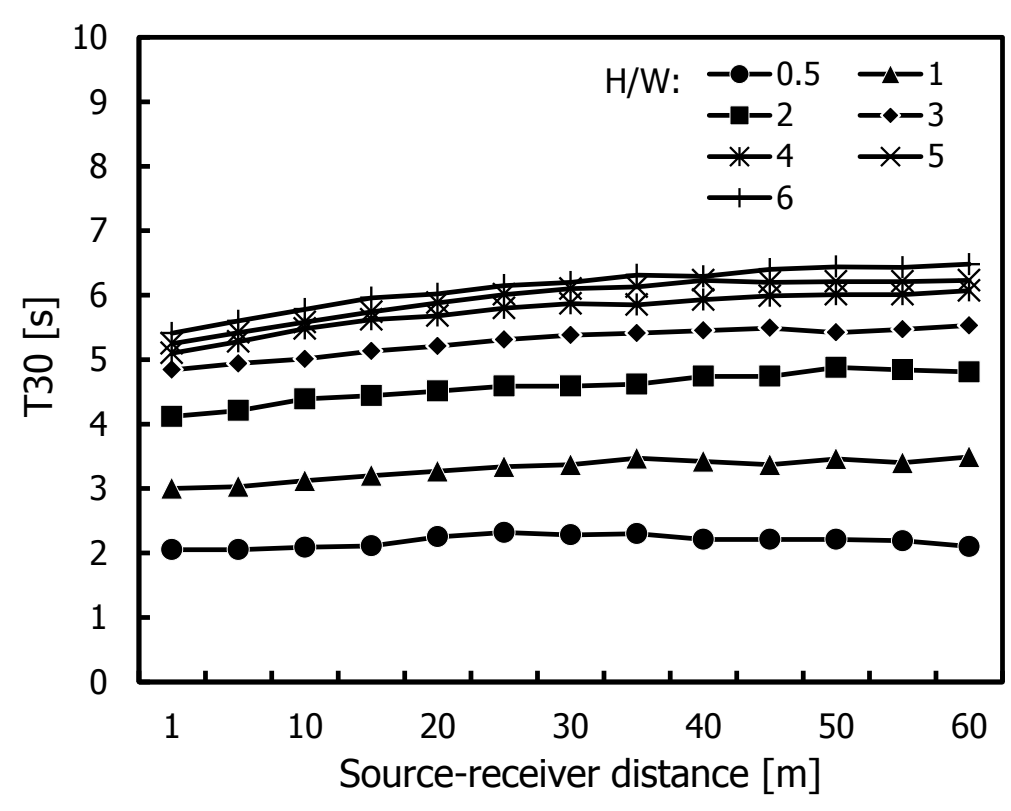

d) 


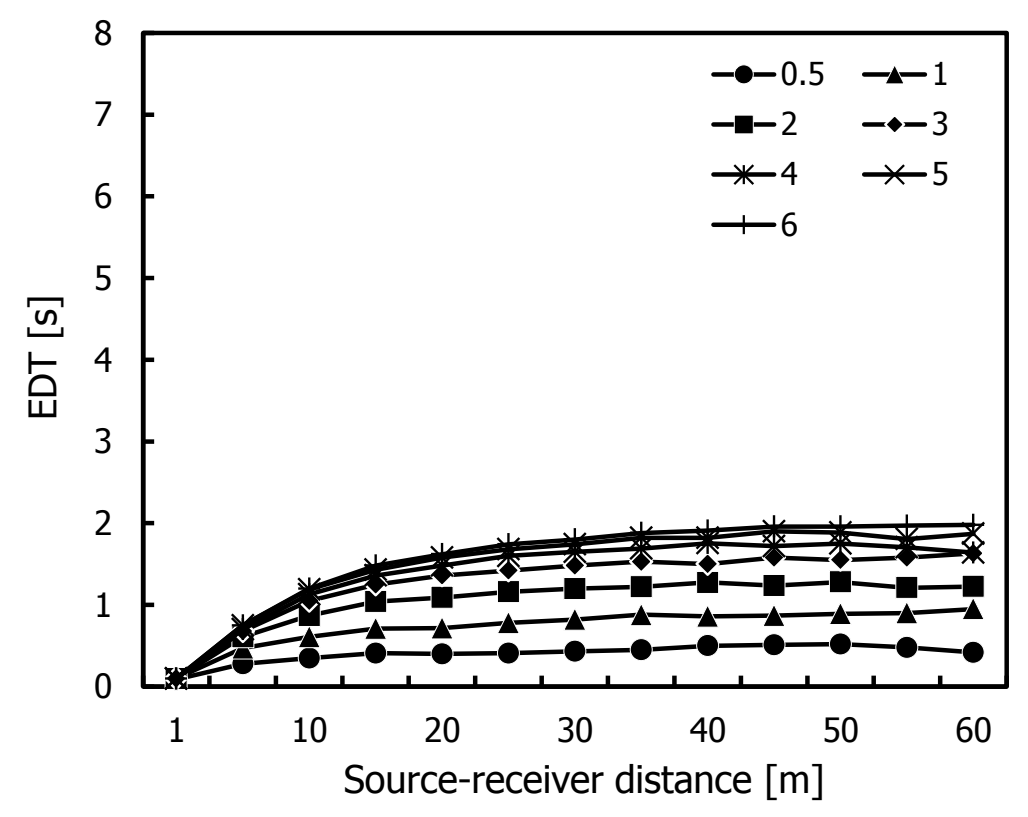

a)

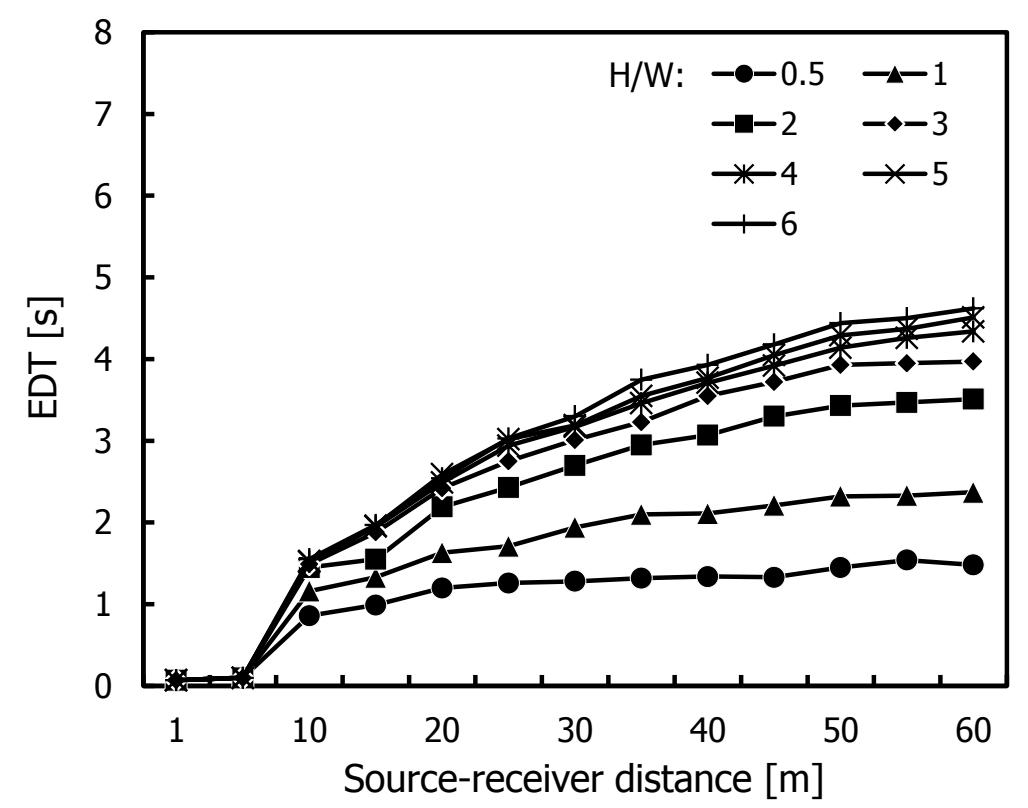

c)

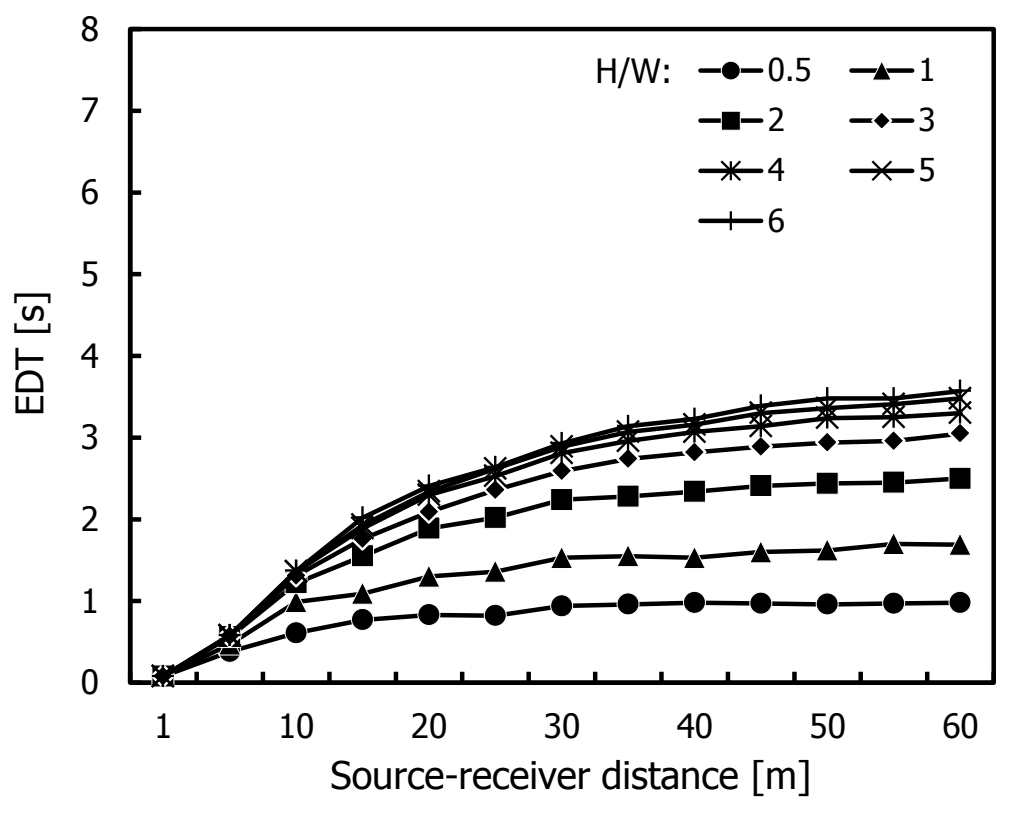

b)

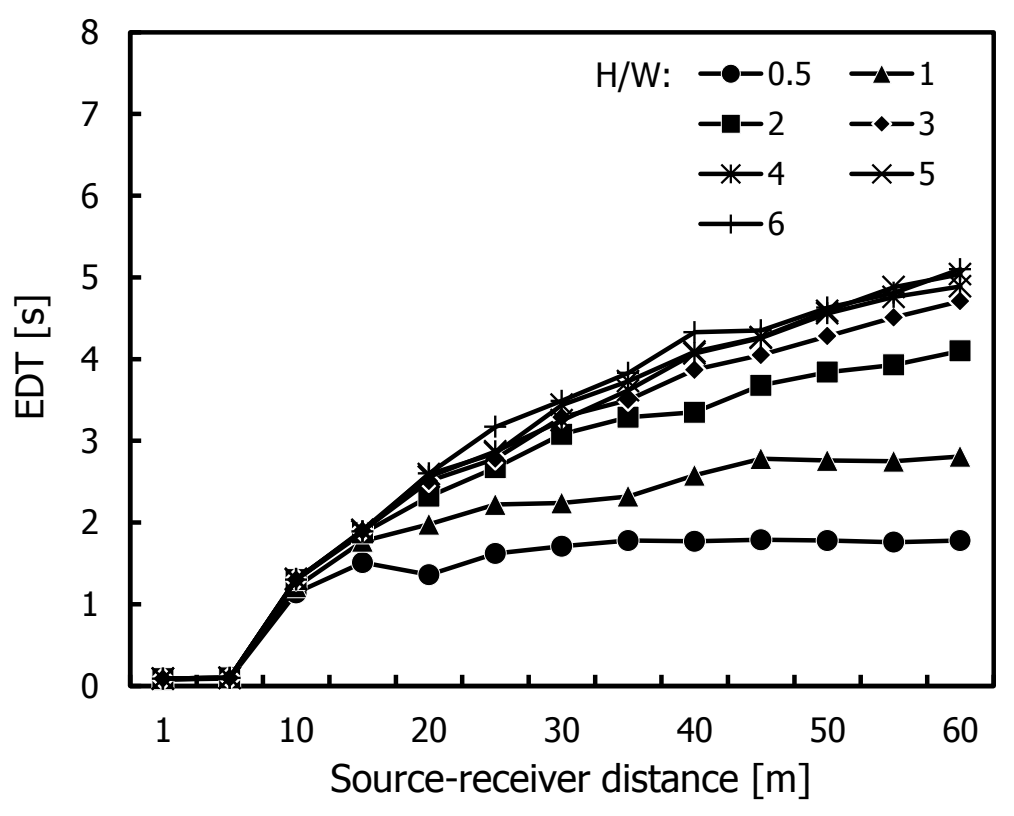

d) 

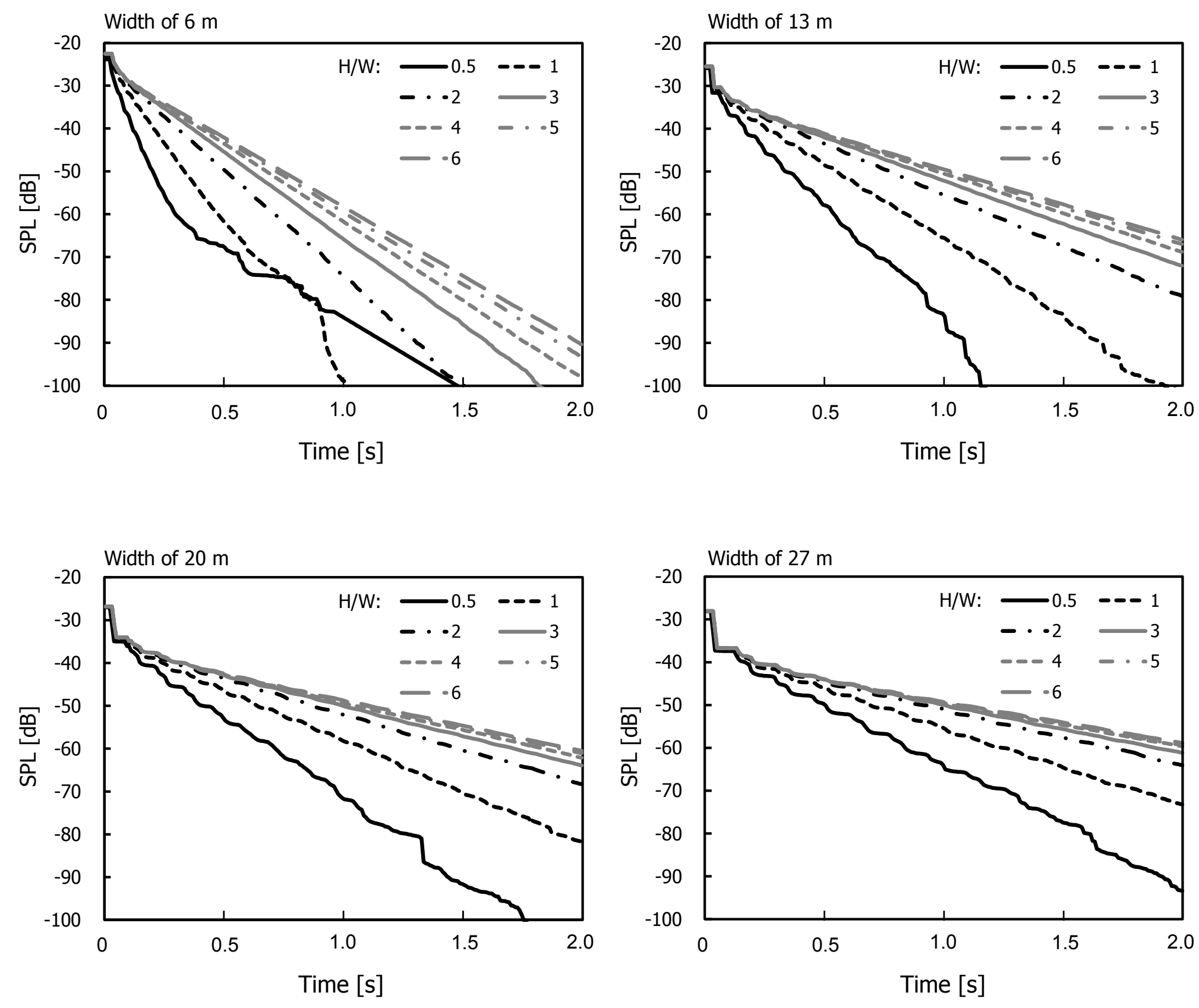
Width of $6 \mathrm{~m}$
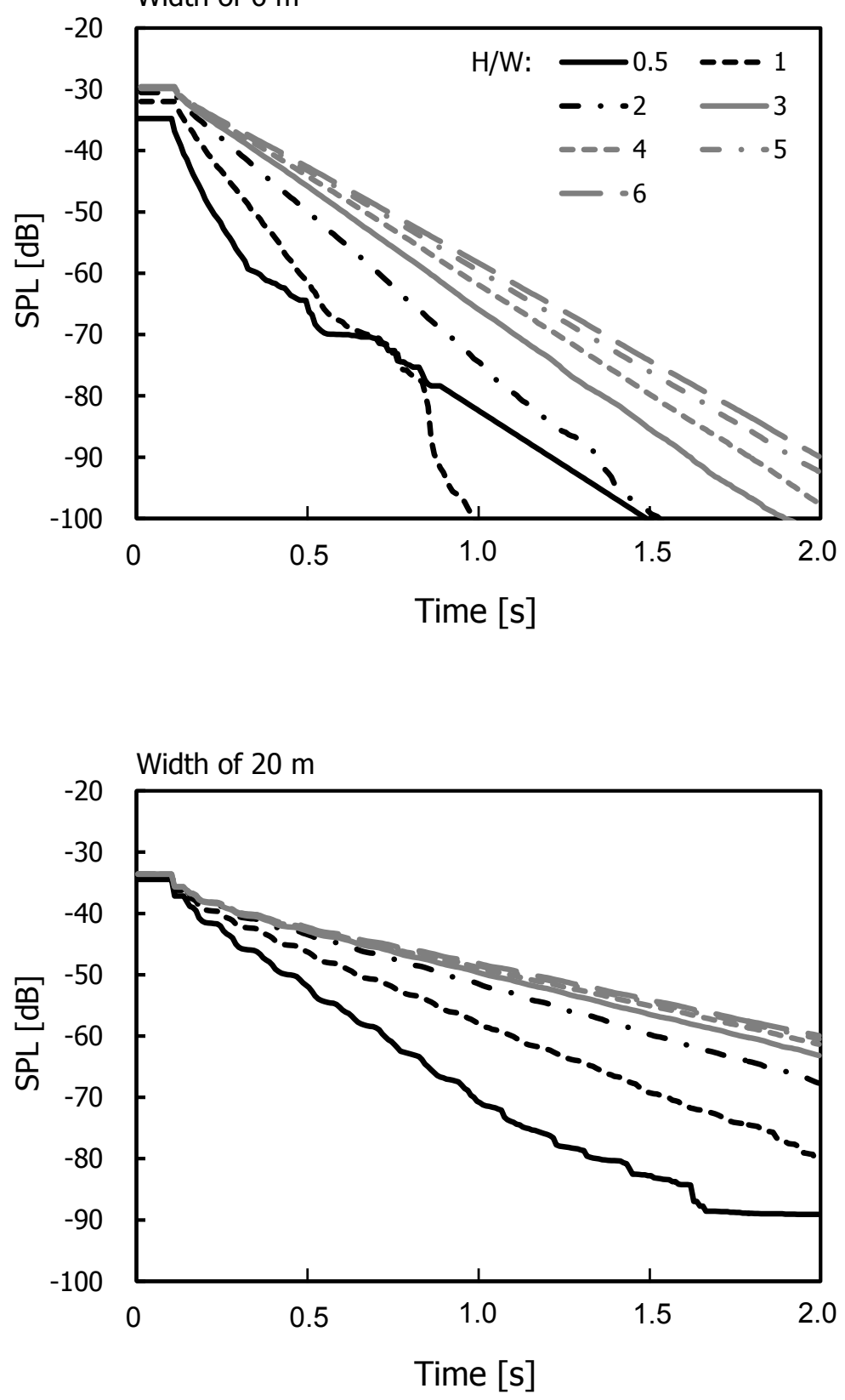

Width of $13 \mathrm{~m}$
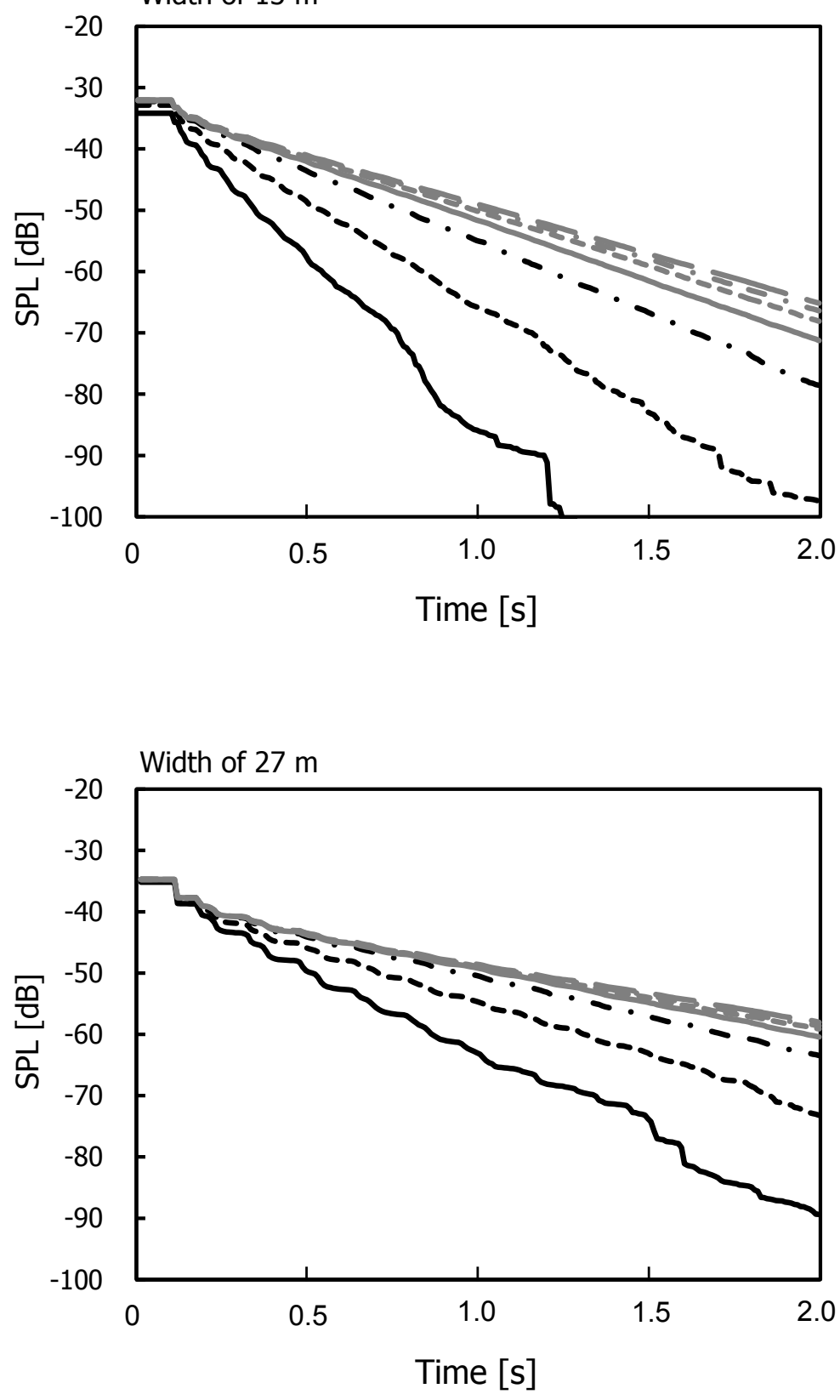

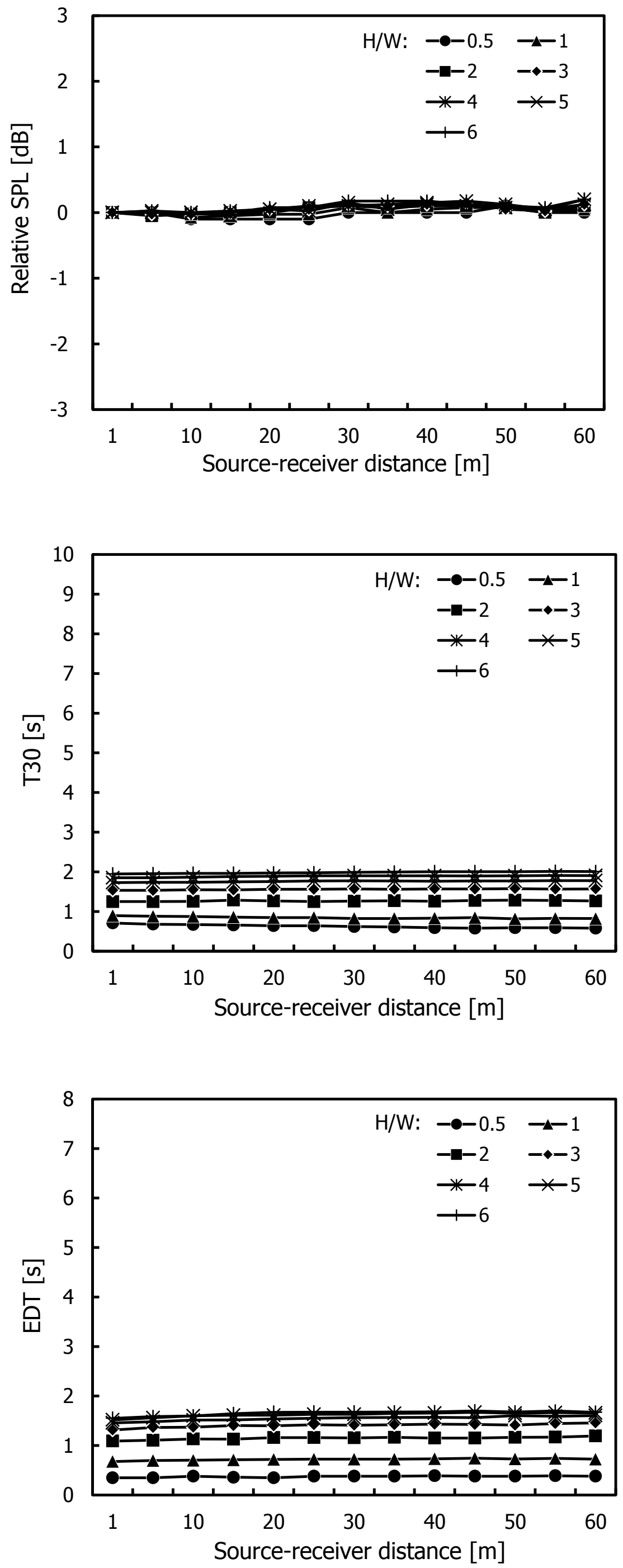

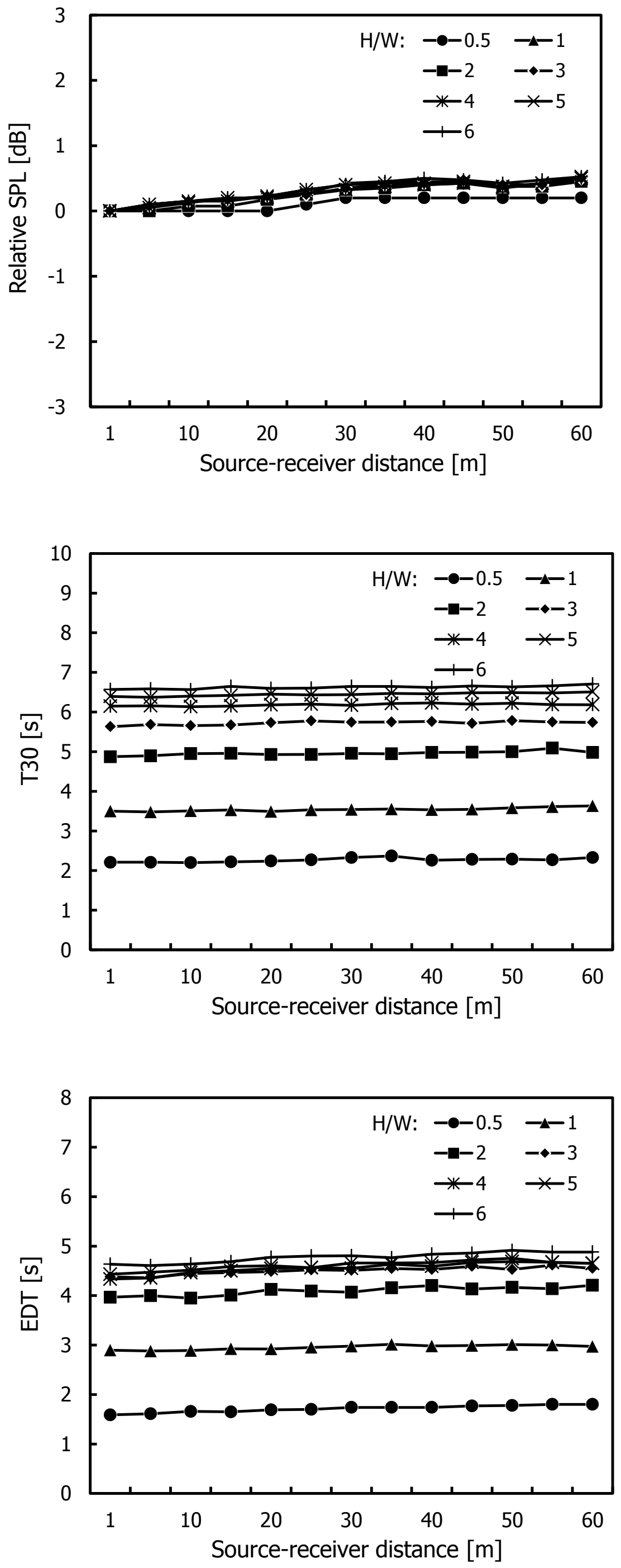

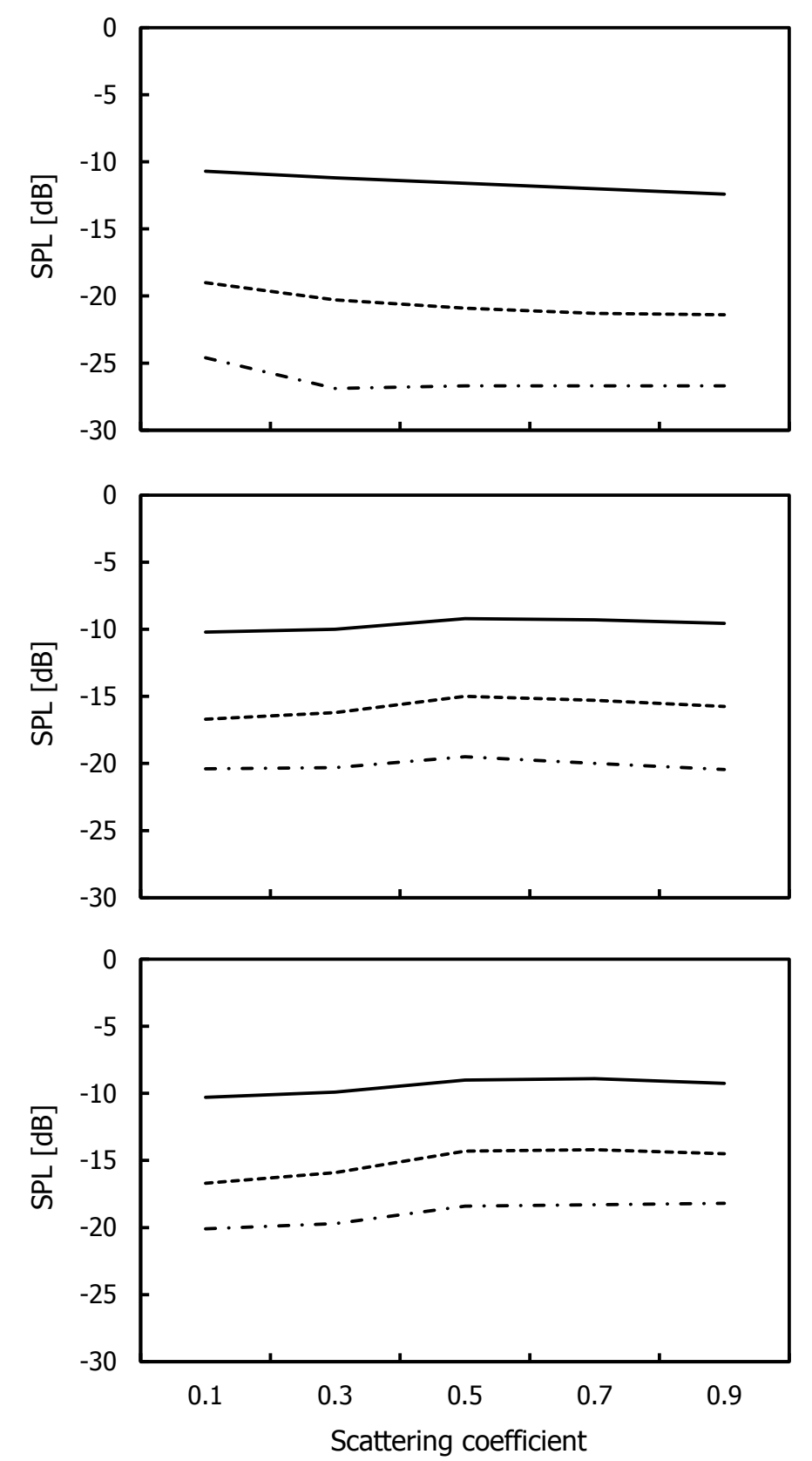
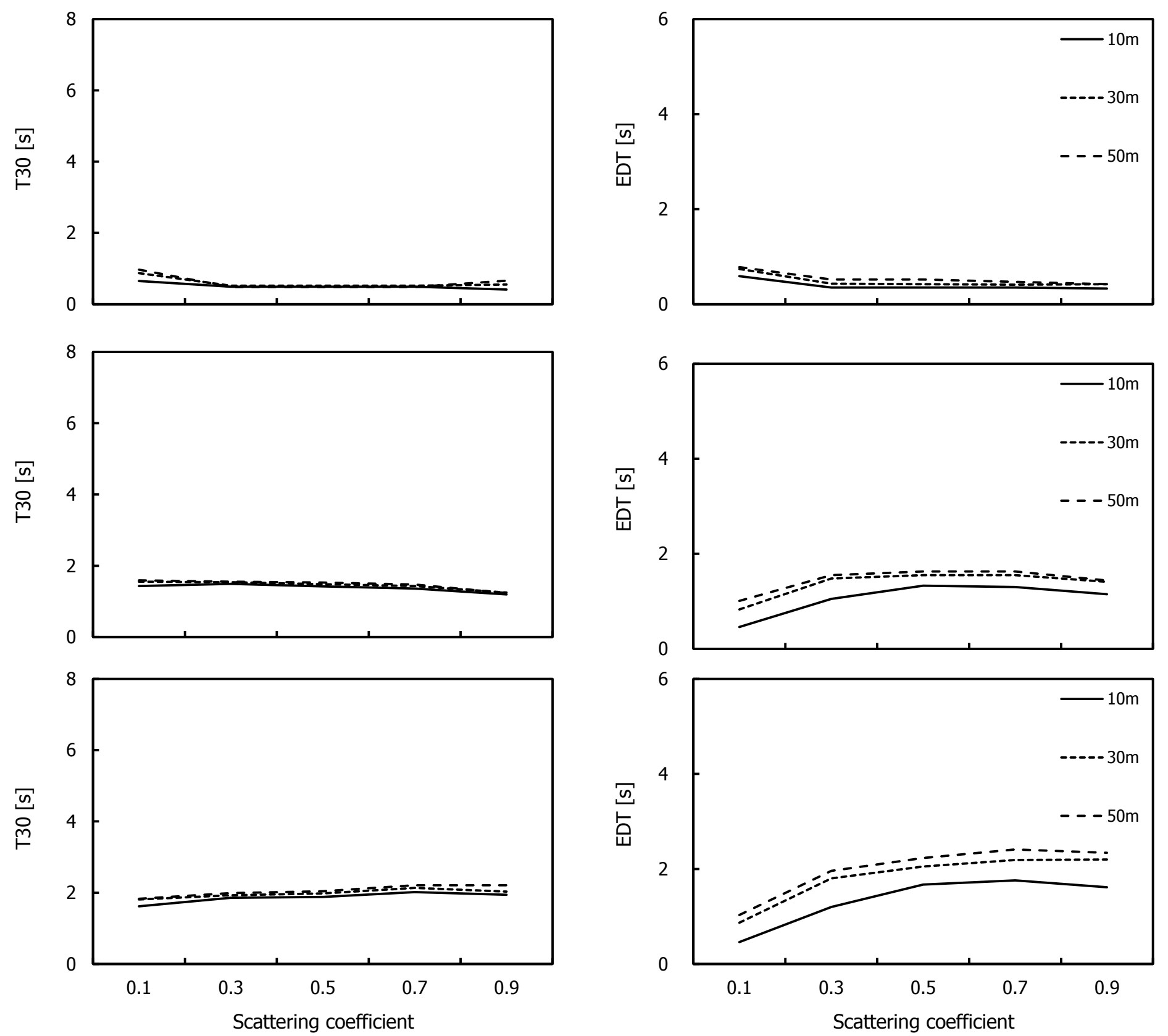

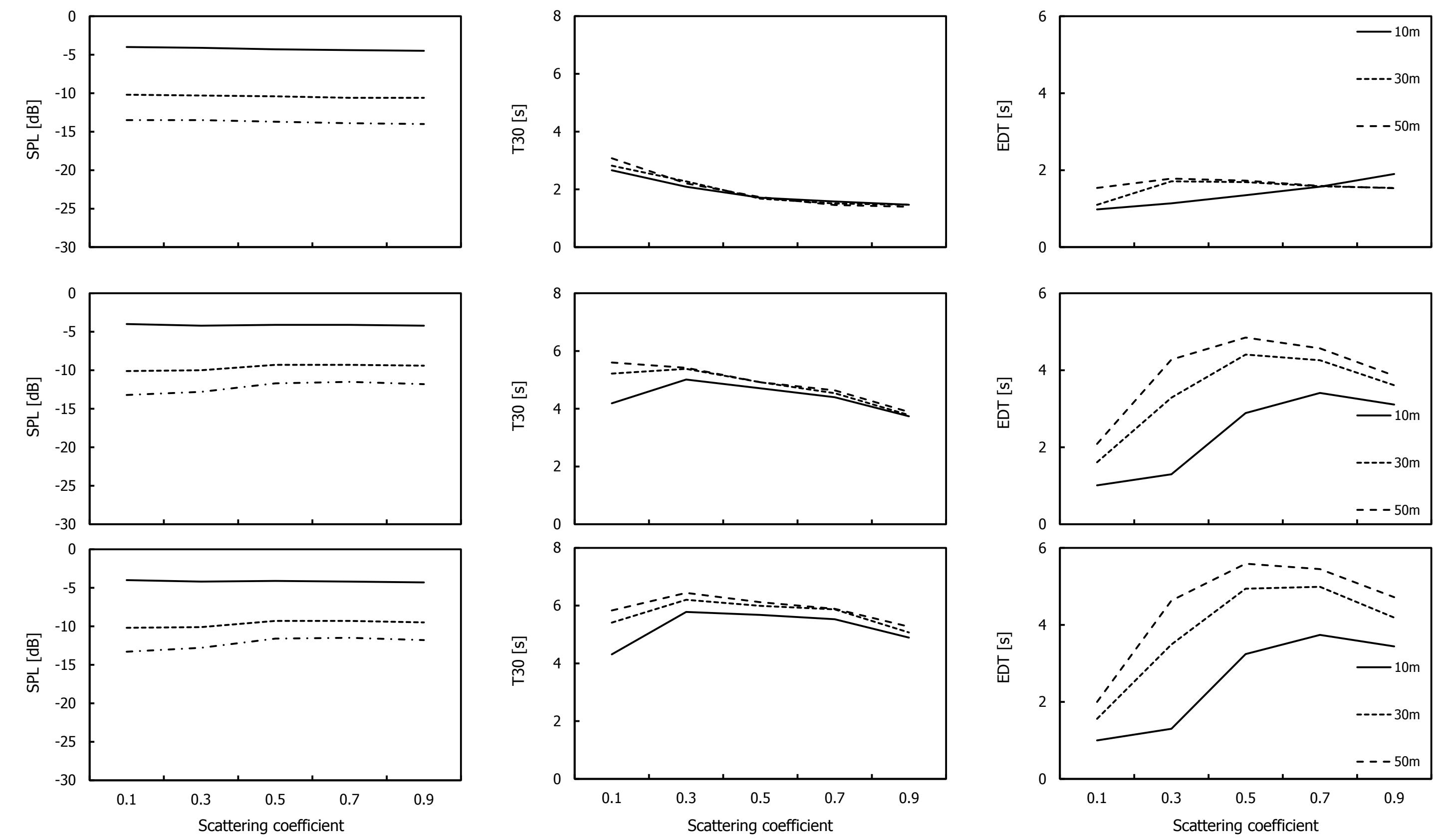